Florida International University FIU Digital Commons

FIU Electronic Theses and Dissertations

University Graduate School

$11-13-2015$

\title{
Enhanced Flexible Materials for Valve Prosthesis Applications
}

Makensley Lordeus

mlour001@fiu.edu

DOI: $10.25148 /$ etd.FIDC000211

Follow this and additional works at: https://digitalcommons.fiu.edu/etd

Part of the Biomedical Engineering and Bioengineering Commons

\section{Recommended Citation}

Lordeus, Makensley, "Enhanced Flexible Materials for Valve Prosthesis Applications" (2015). FIU Electronic Theses and Dissertations. 2315.

https://digitalcommons.fiu.edu/etd/2315

This work is brought to you for free and open access by the University Graduate School at FIU Digital Commons. It has been accepted for inclusion in FIU Electronic Theses and Dissertations by an authorized administrator of FIU Digital Commons. For more information, please contact dcc@fiu.edu. 


\section{FLORDIA INTERNATIONAL UNIVERSITY \\ Miami, Florida}

ENHANCED FLEXIBLE MATERIALS FOR VALVE PROSTHESIS APPLICATIONS

A thesis submitted in partial fulfillment of

the requirements for the degree of

MASTER OF SCIENCE

in

BIOMEDICAL ENGINEERING

by

Makensley Lordeus 
To: $\quad$ Interim Dean Ranu Jung

College of Engineering and Computing

This thesis, written by Makensley Lordeus, and entitled Enhanced Flexible Materials for Heart Valve Prosthesis Applications, having been approved in respect to style and intellectual content, is referred to you for judgment.

We have read this thesis and recommend that it be approved.

Nikolaos Tsoukias

Wei-Chiang Lin

Sharan Ramaswamy, Major Professor

Date of Defense: November 13, 2015

The thesis of Makensley Lordeus is approved.

Interim Dean Ranu Jung College of Engineering and Computing

Dean Lakshmi N. Reddi University Graduate School

Florida International University, 2015 
ABSTRACT OF THE THESIS

ENHANCED FLEXIBLE MATERIALS FOR HEART VALVE PROSTHESIS

APPLICATIONS

by

Makensley Lordeus

Florida International University, 2015

Miami, Florida

\section{Professor Sharan Ramaswamy, Major Professor}

While mechanical, homograft and bio-prosthetic valves have been used in patients for many decades and have made significant improvements in patient morbidity, there is still a distinct need to overcome their limitations. Recently, emerging elastomer heart valves have been shown to be able to better re-create the flow physics of native heart valves, resulting in preferable hemodynamic responses. Unfortunately, elastomers such as silicone are prone to structural failure, which drastically limits their applicability towards the development of valve prosthesis. In order to produce a mechanically more robust silicone substrate, we reinforced it with graphene nanoplatelets (GNPs). Cytotoxicity and hemocompatibility tests revealed that the incorporation of GNPs did not adversely affect cell proliferation or augment adhesion of platelets on the surface of the composite materials. The ECM valves showed good hydrodynamic properties and favorable acute performance compared to a commercially available valve. We conclude that both the Graphene reinforce silicone and the ECM is useful and warrants further evaluation as aortic valve substitutes. 


\section{TABLE OF CONTENTS}

CHAPTER

PAGE

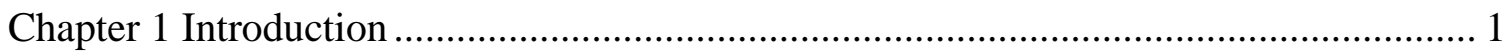

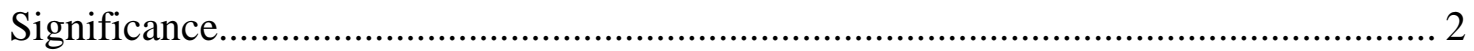

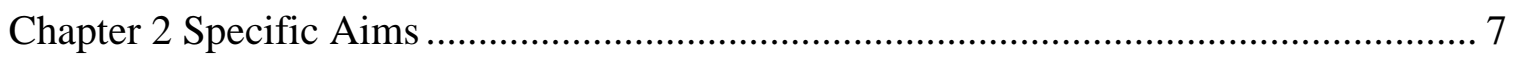

Chapter 3 Literature Review ................................................................................ 8

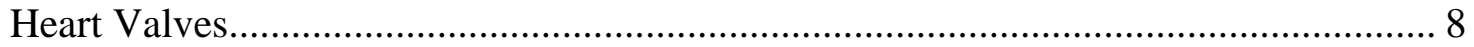

Valvular Diseases - Aortic valve stenosis ............................................................. 9

Valvular Diseases - Mitral Valve regurgitation and prolapse ................................... 10

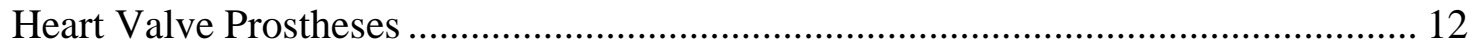

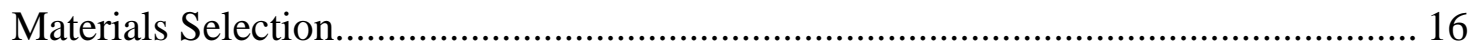

Graphene Nanoparticles......................................................................................... 17

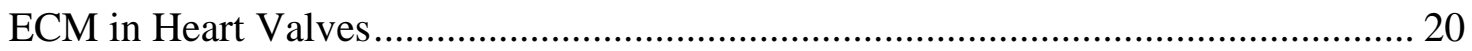

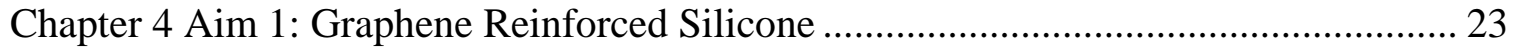

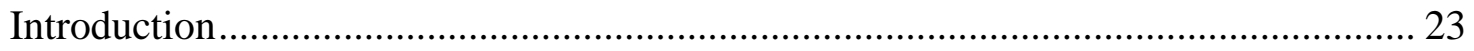

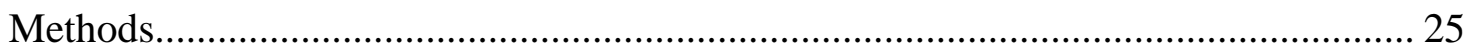

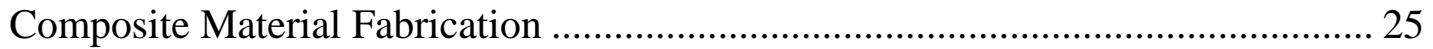

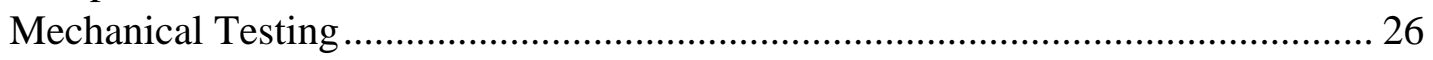

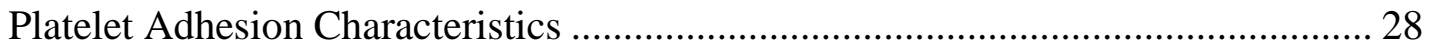

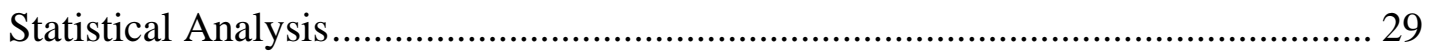

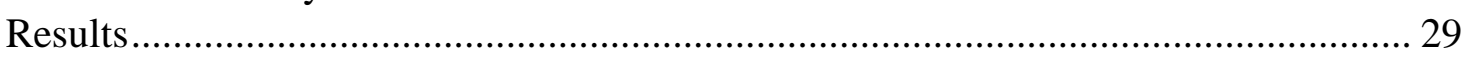

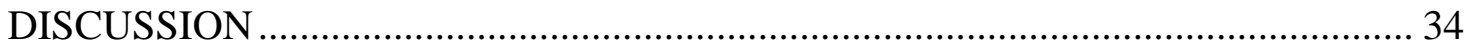

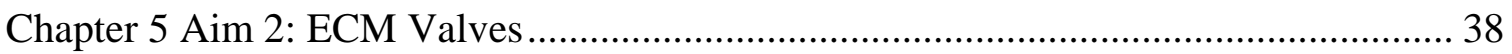

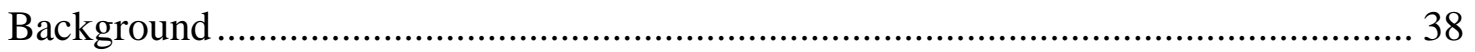

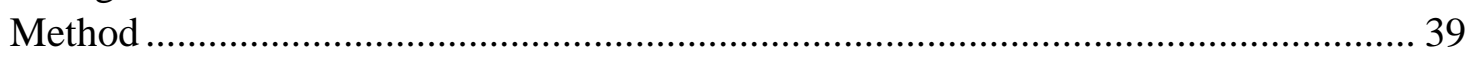

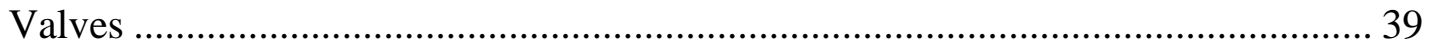

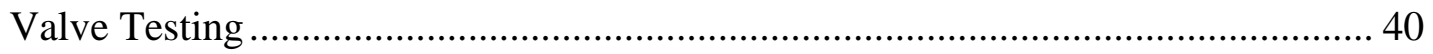

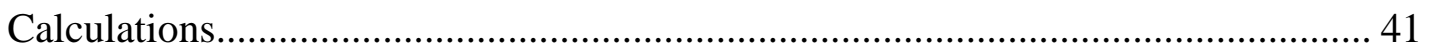

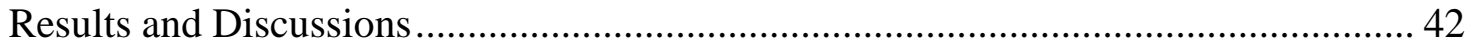

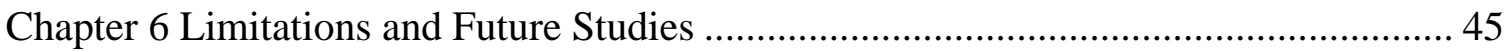

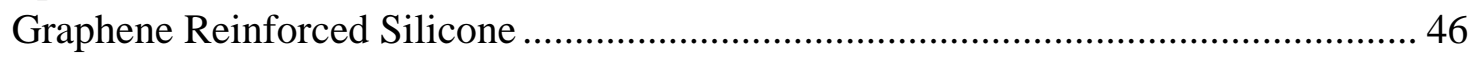

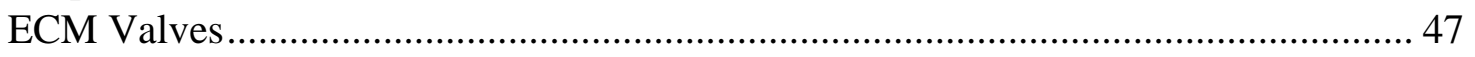

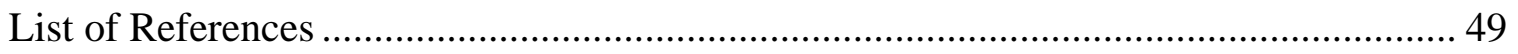




\section{TABLE OF FIGURES}

FIGURE

PAGE

Figure 1: Topographic interrelations of the heart valve. (Dominik \& Zacek, 2010) 8

Figure 2: Gross pathological specimens from patients with aortic stenosis. (A. Wang \& Bashore, 2009)

Figure 3: The heart in systole. A) in normal individuals. B) in patients with both prolapse and mitral regurgitation. (Turi, 2004)

Figure 4: EOA in comparison with GOA. A) a rigid sharp-edged aortic stenosis; B) a funnel-shaped aortic stenosis (Garcia \& Kadem, 2006)

Figure 5: Frabrication of nanocomposite membrane. (Lian et al., 2011)

Figure 6: Load vs displacement curves of graphene/chitosan composites with different amounts of graphene. (Fan et al., 2010)

Figure 7: A, SIS 1 day after implantation, hematoxylin and eosin staining. B, 3 months after implantation. C, 6 months after implantation. D, 12 Months after implantation. E, Native valve. F-H, SIS Valve 12 months after implantation with antibody staining. F, subendothelial von Willebrand factor VIII. G, interstitial smooth muscle cells. H, connective tissue vimentin. (Ruiz et al., 2005).

Figure 8: Set up for tensile testing showing the specimen grips and the test conditions, including an envi-ronmental bath filled with $8 \mathrm{~g} / \mathrm{L}$ saline solution (Bose Electroforce system, Eden Prairie, MN). The temperature of the saline bath was maintained at 37oC during testing.

Figure 9: Silicone-graphene material: (a) control containing only silicone. (b) $250 \mathrm{mg}$ GNP, (c) 75 mg GNP, and (d) 25 mg GNP of graphene per liter of uncured silicone.

Figure 10: A) Mean stress-strain curve of silicone-graphene material ( $n=3$ specimens/group). B) Mean numbers of cyclic stretch withstood by the samples before specimen failure ( $\mathrm{n}=3$ specimens/group). Note that the samples were cyclically stretched from rest to a maximum of $600 \%$ strain at a frequency of 0.05 $\mathrm{Hz}$ until the specimen broke. C) Stress versus number of cycles plot for siliconeonly and silicone-GNP (250 mg/mL). The sudden drop in stress demonstrates the point at which the specimen broke. The plot also shows a corresponding view of the cross-section of the edge where breakage occurred. A few small air bubbles were unavoidably present in the silicone-only samples. Introduction of GNP in the silicone matrix permitted an opportunity to serve as a filler material, thereby eliminating the few void spaces within the substrate. 
Figure 11: For the silicone-only (control) and silicone-GNP materials (25, 75 and 250 $\mathrm{mg} / \mathrm{mL}$ ), A) Fluorescence images showing cell viability after 24 hours or culture; red color indicates mitochondrial staining and blue color is a counterstain of the nucleus. GNP incorporation appeared to have no adverse effect on cell viability relative to the controls since all groups demonstrated robust metabolic activity as shown by the large degree of positive mitochondrial staining. B) Relative survivability of RAMECs after 1,3 , and 7 days $(n=3)$. All groups demonstrated positive proliferation over 1 week with the largest increased observed in the group containing $250 \mathrm{mg} / \mathrm{ml}$ of GNPs within the silicone matrix.

Figure 12: Mean number of platelets on sample surfaces after 35 minutes of exposure to whole blood flow ( $\mathrm{n}=2$ samples/group). Porcine blood was used and perfused across the specimen surfaces at a flow rate of $679 \mathrm{~mL} / \mathrm{min}$. The groups tested comprised of silicone-only, and GNP-silicone composites with the following densities of GNP: $250 \mathrm{mg}, 75 \mathrm{mg}$, and $25 \mathrm{mg}$ of graphene per liter of uncured silicone

Figure 13: Pattern used for aortic leaflets. (Love, 1998)

Figure 14 - schematic representation of the positive pressure period of an aortic forward flow interval from ISO-5840

Figure 15- Aortic and Ventricular pressure profiles for the ECM and Medtronic bioprosthetic

Figure 16- Flow rate of ECM and Medtronic Bioprosthetic valve 


\section{Chapter 1 Introduction}

Heart valves promote coordinated forward blood flow during the cardiac cycle. These valves have leaflets that open and close with each heartbeat. Valve disease such as critical stenosis or regurgitation, is a significant public health problem (Hoffman \& Kaplan, 2002). Valve disease results in approximately 20,000 deaths annually. The direct cost for valve disease in the United States alone has been estimated at \$1 billion per year (Hinton \& Yutzey, 2011). Any one of the four heart valves can be affected; however, the

aortic and mitral valves are the most common for disease. In addition congenital valvular disease such as aortic valve malformation is present in roughly 1 to $2 \%$ of the general population (William C. Roberts \& Ko, 2005).

Typically, when heart valves fail, they are replaced with a heart valve prosthesis. Commercially available heart valve prostheses are divided into two categories: mechanical and bio-prosthetic or tissue heart valves. Mechanical valves include caged ball, tilting disc, and hinged bileaflet valves. Tissue valves include aortic homograft, stent-mounted porcine heterograft and valves fabricated from bovine pericardium.

Mechanical heart valves are extremely durable. The FDA requires heart valves to withstand 10 years of use (Food and Drug Administration, 2010), but there have been cases where the mechanical heart valve has lasted for decades (Emery et al., 2005). These valves are made with very strong materials, such as titanium, Teflon, and pyrolytic carbon. The major problem with mechanical heart valve is thrombus formation. These clots could result in very serious consequences, such as stenosis and myocardia 
infractions as well as present a danger for stroke. To prevent thrombus, the patient must undergo anticoagulant therapy for the rest of their lives. The anticoagulant therapy may results in other complications, such as bleeding and spontaneous abortions (John \& Liao, 2013).

Tissue heart valves are made from animal tissues, such as cow pericardium and pig valves. These valves are treated chemically (fixed with glutaraldehyde) to make the valve inert and reduce the risk of an immune response. The resulting valve is very similar to a human valve and exhibits much better hemodynamics than a mechanical valve. The improved fluid dynamics of the valve decreases the chances of thrombosis and its native tissue structure eliminates the need for anticoagulant therapy (Grunkemeier \& Rahimtoola, 1990). Unfortunately, these tissue valves have limited durability.

Elastomeric heart valves are made from elastomer materials that exhibit similar flexure properties as the native heart valves (Ramaswamy et al., 2013). These heart valve are designed to mimic the human native heart valve and recreate the flow dynamics. One example is a silicone heart valve, which exhibits amazing flow dynamics, but like tissue valves, are not very durable.

\section{Significance}

While mechanical, homograft and bio-prosthetic valves have been used in patients for many decades and have made significant improvements in patient morbidity, there is still a distinct need to overcome their limitations as evidenced by the ten-year mortality rate following valve replacement, which ranges from 30 to 55\% (Edmunds et al., 1997). Research in the use of polymer materials for the fabrication of tri-leaflet valves has been 
ongoing for over 50 years, but has faced substantial hurdles in the facilitation of adequate valve durability. However, new methods in manufacturing and reinforcement of polymer materials have resurrected the appeal of polymer materials for heart valve prosthesis application. One such material that has found renewed interest is silicone. Unfortunately, silicone is prone to structural failure which drastically limits its applicability for heart valve prosthetics (Roe, Kelly, Myers, \& Moore, 1966).

Tissue heart valves also suffer from durability issues, but for reasons associated to depletion of extracellular matrix components such as glycosaminoglycan (GAGs). Tissue valves are much more analogous to native heart valves. They are able to last 5 to 10 years implanted in the body before they fail. This is a huge issue for younger patients that would have to undergo surgery again when the valve fails. Bioprosthetic heart valves fail because of material deterioration and associated calcium phosphate deposits at the high stressed areas. Substantial research has gone into investigating disruption of the extracellular matrix (ECM), especially type I collagen fibrils. Loss of GAGs in heart valves has only recently been under the spotlight for its link with tissue degradation.

Research has shown that GAGs leach out under accelerated fatigue irrespective of bioprosthetic heart valves being fixed with glutaraldehyde crosslinking (Vyavahare et al., 1999). One cause of failure of the bioprosthetic valve is adverse changes in mechanical properties during degradation of the ECM. When the valves degrade, they become stiff and the hydrodynamic properties are significantly hindered, which may also lead to thrombosis and stenosis. One of the functions of GAGs is the maintenance of tissue 
hydration. Loss of GAGs leads to water loss in the valve tissue, which in turn, leads to stiffening of the leaflets.

It is evident that with current technology, we do not from a materials property standpoint, match silicone elastomer and native, chemically fixed tissues to the considerably more durable mechanical valves properties. On the hand as already described, mechanical valves still require life-long anticoagulant therapy, which precludes usage in subpopulation groups such as children, women who may wish to have children and individuals who do not tolerate blood-thinners.

Notably, about $50-60 \%$ of patients with replacement valves either need a reoperation or die within ten years of valve implantation (A. Wang \& Bashore, 2009). To reduce these numbers, less invasive strategies for valve replacement such as percutaneous valve approaches, which are still relatively new, are currently being considered in patients at high-risk for open-heart surgery. The valves available currently for percutaneous approaches all are made using pericardium tissue valves. Stemming from its flexible characteristics, silicone valves would serve as a potential candidate for percutaneous valve replacement. As noted, even when deployed in a minimally invasive manner, pericardium valves are intrinsically not very durable and thus this limitation will remain in percutaneous valve technologies.

Here we proposed that silicone could be reinforced with graphene nanoplatelets (GNPs) to promote its strength and durability for subsequent valve prostheses development. Graphene is known for its high-strength (Lee, Wei, Kysar, \& Hone, 2008). Human cells also exhibit a minimal cytotoxic response to graphene (Santos et al., 2012). The primary 
objective therefore was to characterize the response of silicone substrates to static and cyclical loading conditions with and without graphene reinforcement and, in addition, to assess whether the graphene-silicone composites had altered cytotoxicity and platelet adhesion properties relative to the silicone substrate alone.

We were also interested in investigating the prosthetic valves made of an ECM 'bioscaffold' material. The ECM material is manufactured by commercial vendors (e.g. CorMatrix, Roswell, GA) and acts as an acellular bioscaffold that is able to allow the patients cells to populate and remold the tissue. The material is produced from porcine small intestinal submucosa (SIS), which is located between the mucosal and muscular layers of the small intestine. The SIS is removed and decelluarized, leaving the ECM intact. These valves have already been implanted into newborn patients with critical valvular defects (i.e., compassionate care cases) by doctors at Joe DiMaggio Children’s Hospital (Holywood, FL) that we are collaborating with; over a year later, the valves are still functioning flawlessly and the patients are doing well. Therefore, with the wealth of clinical data that the doctors have combined with the hydrodynamic data that could be obtained in vitro, it may be possible to further optimize functionality of the ECM valves.

The objective of my thesis is to identify protocols and processes that would offer potential alternative solutions to existing limitations in current, commercially available valve technologies

Thus in the area of emerging valve replacement technologies, we hereby propose examining enhanced elastomeric materials for the valve application and further 
characterizing the functional properties of ECM valves currently being used clinically on a controlled and limited basis. 


\section{Chapter 2 Specific Aims}

Specific Aim 1: Develop and characterize a graphene reinforce silicone material for potential application in valve prosthesis development.

Specific aim 2: Analysis of ECM valve hydrodynamic properties and co-relation to clinical data in the aortic and mitral valvular positions. 


\section{Chapter 3 Literature Review}

\section{Heart Valves}

There are four valves situated in the heart; the tricuspid and pulmonary valves on the right-sided heart chambers and the mitral and aortic valves on the left-sided heart chambers. Morphologically, these valves are divided into two atrioventricular (mitral and tricuspid) and two semilunar (pulmonary and aortic valves(Dominik \& Zacek, 2010). The normal location could be seen in Figure 1.

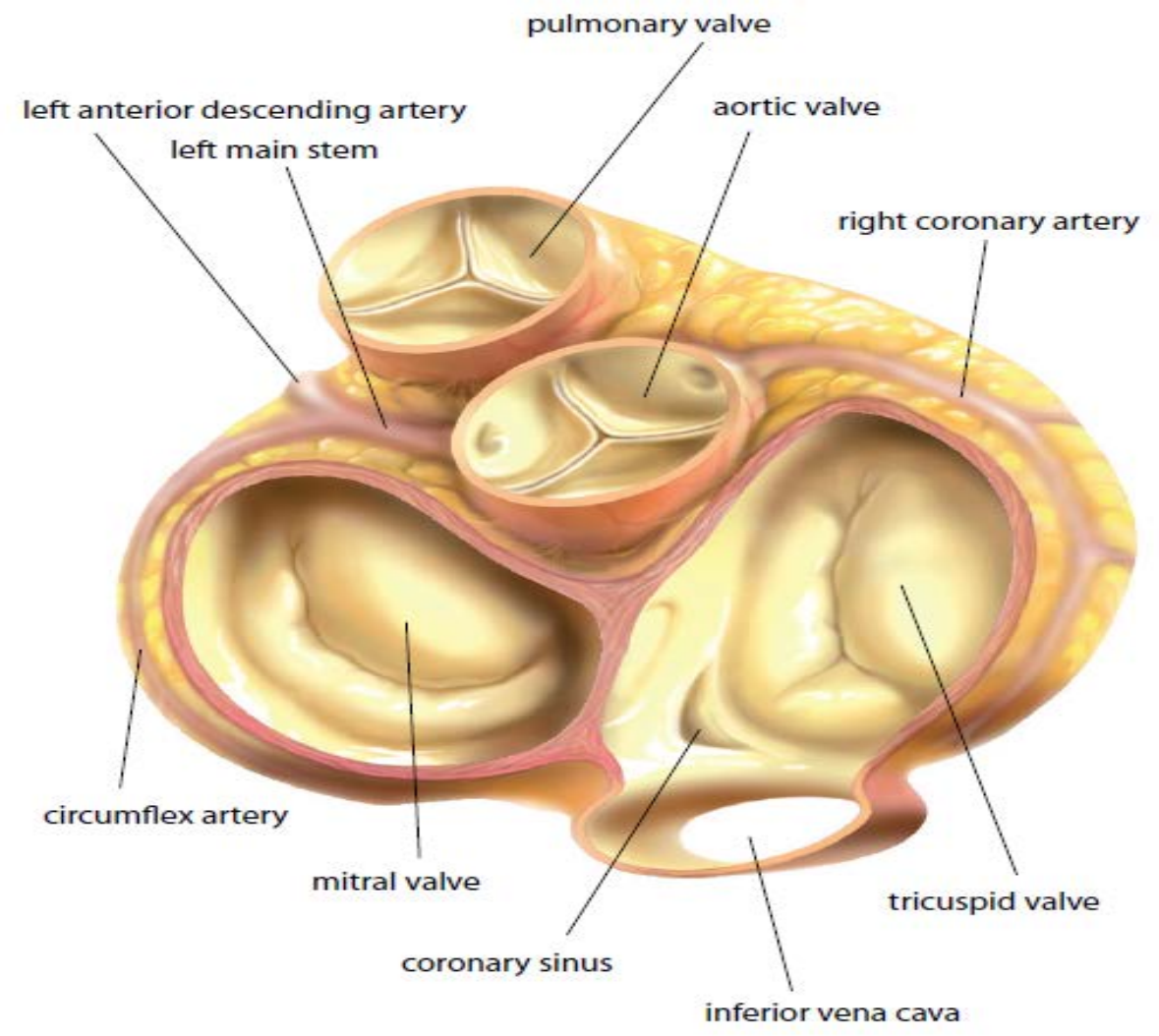

Figure 1: Topographic interrelations of the heart valve. (Dominik \& Zacek, 2010)

The aortic valve is situated in the left ventricular outflow tract and consists of three semilunar cusps and their adjacent sinuses of Valsalva. The aortic valve does not have an 
anatomically defined annulus. The mitral valve is a bileaflet atrioventricular, located between the left atrium and the left ventricle. The triscupid valve is situated between the right atrium and the right ventricle and prevents back flow into the right atrium. The pulmonary valve is a tricuspid semilunar valve in the right ventricular outflow tract. The sinus and leaflets are similar to the aortic valve, but thinner (Dominik \& Zacek, 2010).

\section{Valvular Diseases - Aortic valve stenosis}

After systemic hypertension and coronary heart disease, aortic stenosis is the third most fatal heart disease(William Clifford Roberts \& Ko, 2009). The three major causes of aortic stenosis are atherosclerosis, congenitally malformed valves, and rheumatic heart disease.

Aortic stenosis is a disease in which there is a progressive narrowing of the aortic valve opening causing obstruction to the left ventricular outflow. This leads to an increase in pressure in the left ventricular outflow. The most common location of artic stenosis is at the valve as seen in Figure 2.
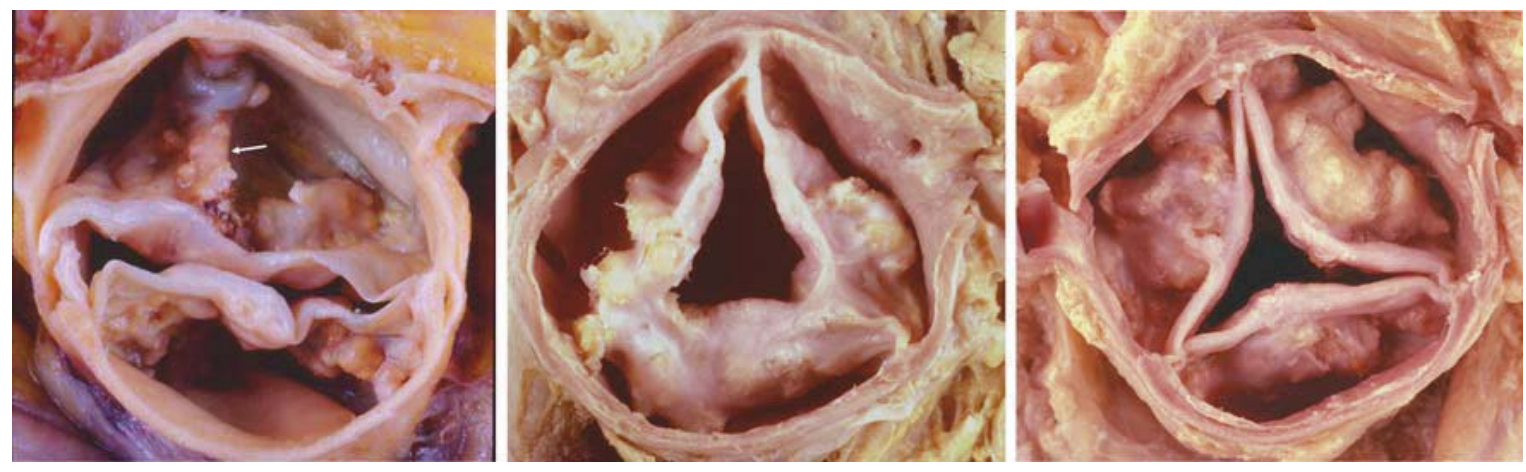

Figure 2: Gross pathological specimens from patients with aortic stenosis. (A. Wang \& Bashore, 2009)

The most common congenital heart disease is bicuspid aortic valve, occurring in approximately $2 \%$ of the population. Bicuspid aortic valve stenosis is the most common 
reason for aortic valve replacement in patients under the age of 70 . The most common cause of aortic stenosis in older patients is senile degenerative aortic stenosis due to degenerative changes with calcific deposits at the base of the aortic valve cusps.

When the stenosis reaches a critical level, the left ventricle is overwhelmed by the high afterload and systolic function begins to decrease. Further afterload excess, myocyte degeneration and fibrosis begin to occur, leading to irreversible left ventricular systolic dysfunction. Even with severe obstruction, many patients with aortic valve stenosis may remain asymptomatic for many years. Symptoms such as angina, dyspnea, and syncope start to appear after a long latent period. The ACC/AHA Valvular Heart Disease guidelines committee have defined the criteria for severity of aortic stenosis based on hemodynamics (Table 1)

\section{Table 1: Severity of stenosis based on hemodynamics}

\begin{tabular}{|l|c|c|c|}
\hline $\begin{array}{l}\text { Severity of aortic } \\
\text { stenosis }\end{array}$ & $\begin{array}{l}\text { Aortic valve } \\
\text { area } \mathbf{( c m} 2)\end{array}$ & $\begin{array}{l}\text { Mean gradient } \\
(\mathbf{m m H g})\end{array}$ & Peak velocity (m/s) \\
\hline Mild & $>1.5$ & $<25$ & $<3.0$ \\
\hline Moderate & $1-1.5$ & $25-40$ & $3.0-4.0$ \\
\hline Severe & $<1.0$ & $>40$ & $>4.0$ \\
\hline Critical & $<0.6$ & $>60$ & $>5.0$ \\
\hline
\end{tabular}

\section{Valvular Diseases - Mitral Valve regurgitation and prolapse}

Out of the heart's 4 valves, the mitral is the most complex and the one most commonly associated with diseases. The valve could be affected by 3 main types of conditions, stenosis, regurgitation, and prolapse. Unlike the aortic valve, stenosis is the least common of the 3 in the mitral valves, accounting for less than $1 \%$ of the cardiac diagnoses in the United States (Turi, 2004). In mitral regurgitation, the valve does not seal completely 
during contraction of the left ventricle and blood leaks from the ventricle to the atrium. One typical cause of regurgitation is enlargement of the left ventricle, where the ring of the mitral valve is stretched, resulting in the leaflets not closing adequately.

Valve prolapse is the most common type of mitral valve diseases. It accounts for about $5 \%$ of the population, occurring most frequently in women. In prolapse, the leaflets of the mitral valve bulges backwards during valve closure, see Figure 3. Mitral valve prolapse is caused by valvular abnormalities of valvar tissue, geometric disparities between the left ventricle and mitral valve, or various connective tissue disorders. A vast majority of patients with mitral valve prolapse has normal life expectancy and have no long-term medical problems associated with the condition. There is a small subset of patients that develop serious complications, such as infective endocarditis, sudden cardiac death, and severe mitral regurgitation (Hayek, Gring, \& Griffin, 2005) 

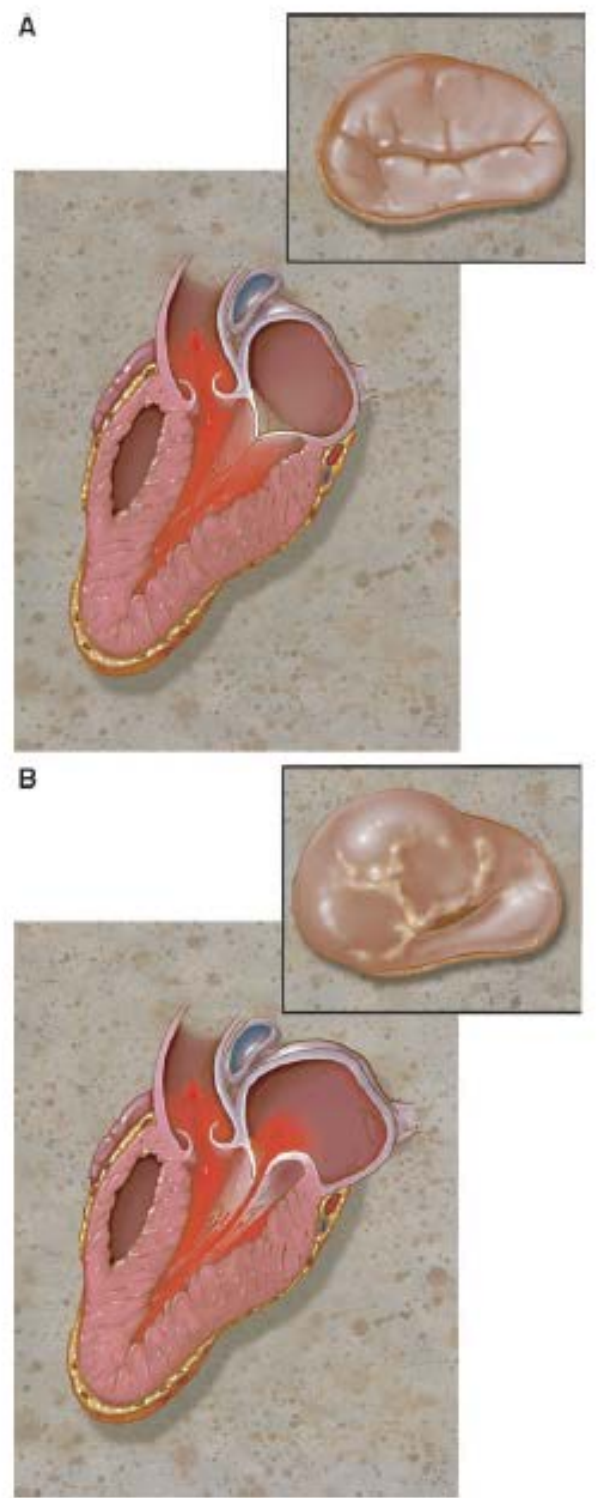

Figure 3: The heart in systole. A) in normal individuals. B) in patients with both prolapse and mitral regurgitation. (Turi, 2004)

\section{Heart Valve Prostheses}

There are two main types of artificial heart valves available commercially. The first category is mechanical valves that are assembled from hard plastic materials, titanium or other metallic alloys. The other category is biological valves that originate from 
biological tissue and which are chemically treated with gluteradehyde to render the tissue inert.

Hemodynamically, the effective orifice area (EOA) is the most important parameter of both mechanical and bioprostheic valves. The effective orifice area is different from the geometric orifice area (GOA), see Figure 4, which is the whole inner area of the valve including the space that contains the leaflets, struts, and other mechanisms of the valve. The EOA is the portion of the valve that blood really flows through. The effective orifice area is usually one quarter or one third smaller than the geometric orifice area.
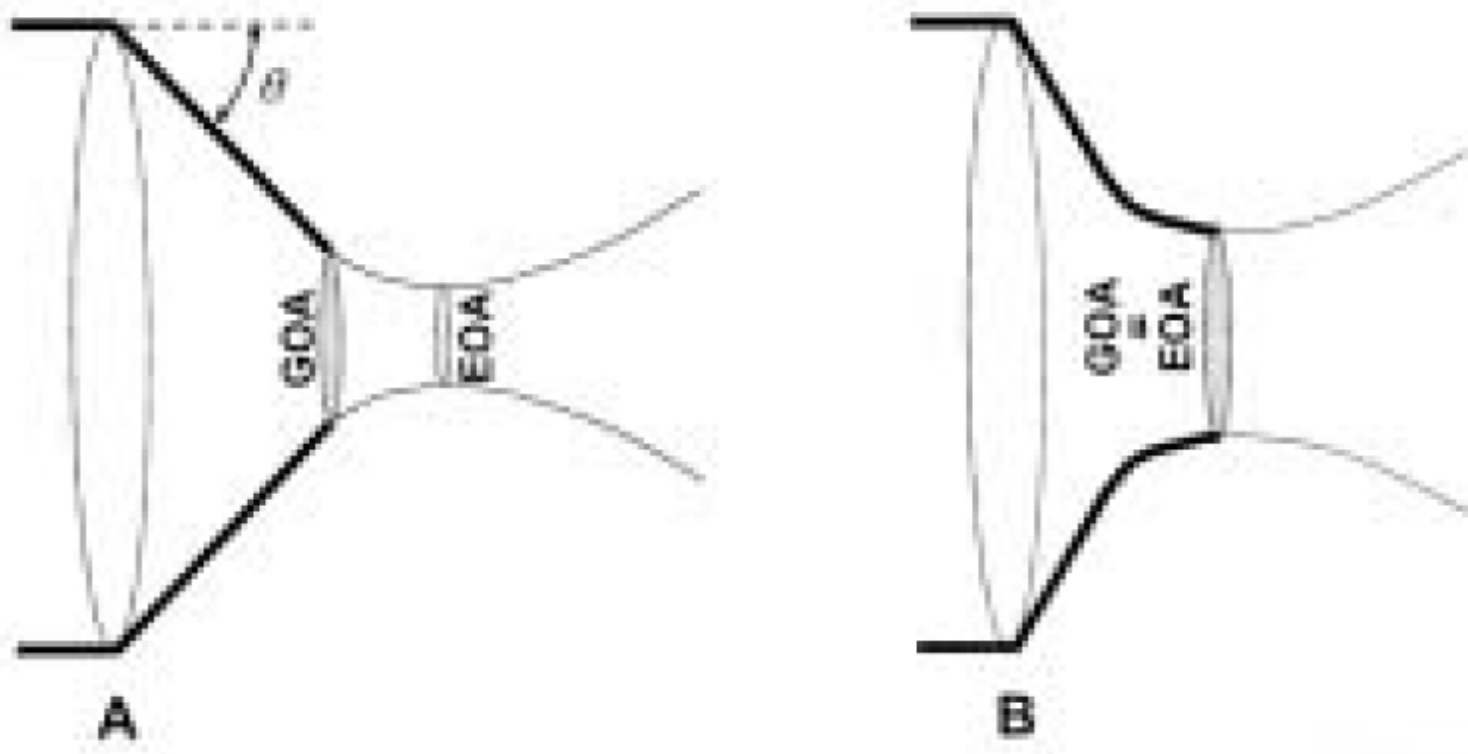

Figure 4: EOA in comparison with GOA. A) a rigid sharp-edged aortic stenosis; B) a funnel-shaped aortic stenosis (Garcia \& Kadem, 2006) 
Mechanical heart valves were the first developed and implanted in patients in the 1960s and are constantly developed and refined to improve hemodynamic and biocompatibility. There are three main types of mechanical valves: caged-ball, disc, and bileaflet valves.

The Starr-Edwards valve is the most well-known caged-ball valve. The 6120 and 1260 models were developed in the late 1960s as mitral and aortic valves, respectively. They are still being manufactured without any modifications and were implanted until 2007 (Mann, Zipes, Libby, Bonow, \& Braunwald, 2014). Patients that were fitted with a ball and cage valve showed hemodynamic improvements but they suffered from very frequent thromboembolic complications. To reduce the complications, caged valves were developed with cloth covers. After several weeks or month after implantation endothelial cells grew within the cover allowing the valve to be endothelialized, resulting in the blood not coming into contact with a foreign surface (except the ball). However, several years later, the cloth would tear, which would then initiate thrombus formation. This led to significant hemolysis and reoperations to replace the artificial valve.

Disc valves were also introduced in the 1960s after the ball and cage valves. The first ones were non-tilting disc valves, which had a low profile design, making them easier to implant and have very little regurgitation. Unfortunately, the valves had very high flow gradients and significant turbulence, which lead to frequent thromboembolic complications and high hemolysis. These valves were replaced by modern tilting disc valves. The tilting mono disc valves were the most frequently implanted valves in the 1970s and 1980s. The Medtronic-Hall valve is the most frequently implanted disc valve worldwide and has been used clinically without modifications since 1977. Since the mid- 
1980s, the mechanical bileaflet valves have become the most frequently implanted valves in the world, especially the St. Jude Medial valve.

Biological valves were developed to reduce the risk of serious hemocompatibility complications that are associated with mechanical heart valves, such as thrombosis, embolism, and excess bleeding. The most frequently implanted tissue valves are xenografts. Xenografts are prepared from the tissues of other species. They are usually mounted on a cloth-covered stent, which could be made from stellite, titanium, or plastic. The stent could be slightly flexibly to absorb stress and prolong the xenograft's durability, and is covered in Teflon or polypropylene. The valves either are porcine aortic valves or assembled from bovine pericardium. The valves are usually processed with a proprietary treatment and stored in glutaraldehyde.

Stentless bioprostheses were introduced in 1988 and implanted in the aortic position. They don’t have a stent or a sewing cuff. Stentless bioprosthetic valves allow a larger valve to be implanted than would be possible with a stented valve, resulting in a larger EOA. Stentless bioprosthetic valves have shown superior hemodynamic features and more complete regression of left ventricular hypertrophy(Jin, 2002; Westaby et al., 2000). Research data has proved no superiority of the stentless valves over stented valves in long-term studies, particularly randomized clinical trials(Ali et al., 2007; Bové et al., 2006; Cohen et al., 2002; Desai \& Lodge, 2009).

Allografts are another option for tissue valves implantations. Allografts are harvested from human cadaver aortic valves. The explanted allograft valves are treated with antibiotic solution and frozen in stored in liquid nitrogen for up to 5 years. When the 
valve is defrosted, viable fibroblast is present but the endothelium is not preserved. The lack of an endothelium reduces the allograft antigenicity and eliminates the need for immunosuppression after implantation. Allografts are more difficult to implant and have similar rates of degeneration as bioprosthetics, so they are used infrequently. Allografts are less susceptible to infection than bioprosthetics and mechanical valves and are used mostly for aortic valve replacement for infective endocarditis (O’Brien et al., 2001).

Autograft biological tissue could also be used for valve replacements. The Ross procedure involves the replacement of the aortic valve with a patient's own pulmonary valve. An allograft pulmonary valve is used to substitute the original pulmonary valve. The Ross procedure presents as currently the only approved procedure wherein a living valve substitute is used. However, controversies related to removal of a healthy pulmonary valve have contributed to heightened research in tissue engineering of heart valves, currently an active research area.

\section{Materials Selection}

As mentioned, mechanical valves, made with metals and hard plastics, offer superior durability, while bioprosthetic valves, made of porcine and bovine tissue, offer favorable hemodynamics. Synthetic elastomeric materials allow the possibility of engineering a material to provide the best of both of these types of valves. Polyolefin (Kidane et al., 2009) and nonreinforced silicone (Kiraly et al., 1982) have been tested as leaflet materials which function very well, but ultimately show inadequate durability.

Polytetrafluoroethylene (PTFE), commonly known as Teflon, is a highly crystalline fluorinated homochain polymer (Fox \& Zisman, 1950). It is known for its inertness and 
low surface energy due to the strengths of the C-C and C-F bonds. This usually leads to good biocompatibility, which is why PTFE could be found in many biomedical devices. But valves made of PTFE have shown acute thrombosis and macroscopic calcification in the commissural areas(Nistal et al., 1990). A tricuspid valve made of PTFE fabric was made and implanted in 23 patients (Braunwald \& Morrow, 1965). 13 of the patients required reoperation. The valves failed due to stiffening, tearing, and some calcification.

Research into polyurethanes have resulted in a flexible and mechanically strong material, but animal studies found degradation of the polyurethane surface structure, which was accelerated by calcified material penetration the polymer (Kolff \& Yu, 1989; Wheatley et al., 2000).

Poly(styrene-b-isobutylene-b-styrene), known as SIBS, has also been investigated for heart valve applications. SIBS is a biostable thermoplastic elastomer that has mechanical properties in between silicone and polyurethane and is highly degradation resistant (Pinchuk et al., 2008). SIBS impregnated in a Polyethylene terephtalate (PETE) mesh showed no significant difference in thrombogenicity in a ventricular assist device compared to mechanical and bioprosthetic valves (Yin et al., 2005). However, in a 20week in vivo study conducted in Ovine, surgically implantable valves had calcification and thrombogenic responses (Q. Wang et al., 2010).

\section{Graphene Nanoparticles}

The modification of graphitic fillers usually enhances their interfacial interaction with elastomer chains, thereby leading to better properties. The nanodimension and aspect ratio of graphene make it's elastomer nanocomposites superior to all other graphitic 
derived composites, provided robust dispersion of the filler is achieved (Sadasivuni, Ponnamma, Thomas, \& Grohens, 2014).

Though the conventional direct blending method provides sufficient torque to disperse the fillers in rubber matrices, the high viscosity of the material often causes non-uniform dispersion of the graphite platelets. Solution mixing has been widely reported as an effective fabrication technique due to the ease of processing graphite derivatives and graphene in water or organic solvents(Lian et al., 2011). The colloidal suspensions of graphene-based materials are mixed with the desired elastomer by simple stirring or shear mixing, (Figure 5). Sonication is often employed to better disperse the graphitic fillers. 


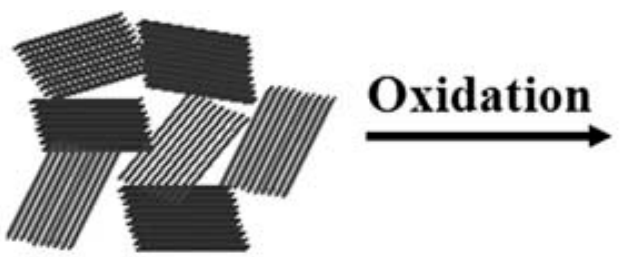

(1)

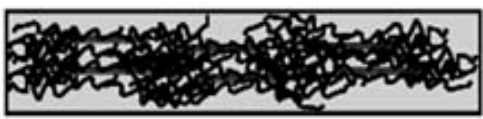

(6)

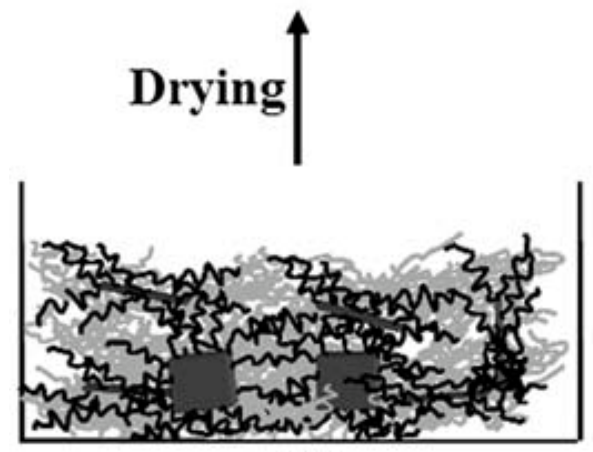

(5)

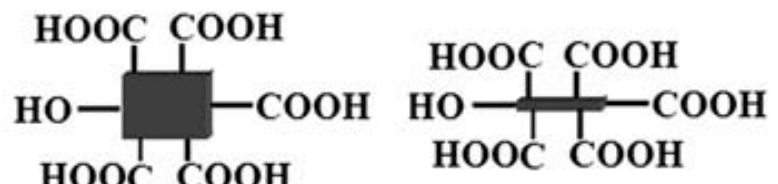

(2)
Cationic
Surfactant
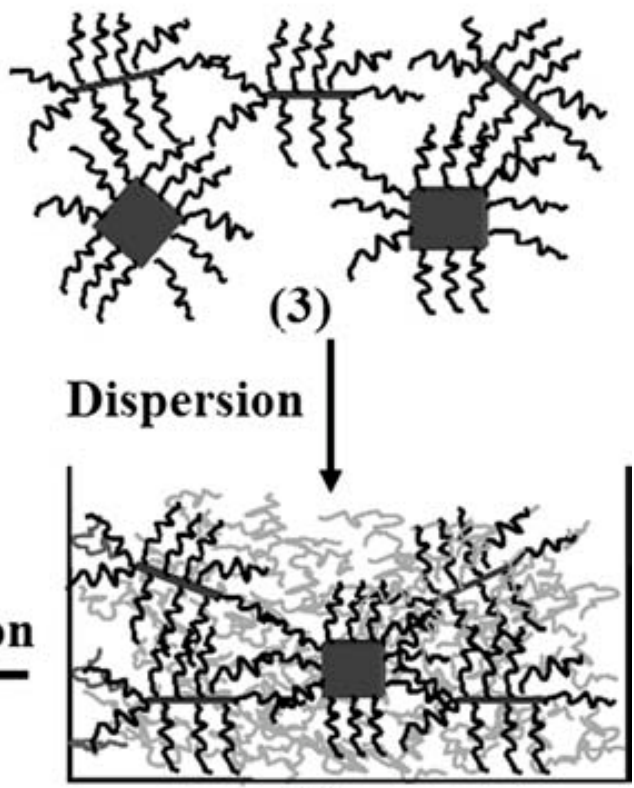

(4)

Figure 5: Frabrication of nanocomposite membrane. (Lian et al., 2011)

Polymer composites containing graphene possess good thermal conductivity and mechanical stiffness(Fan et al., 2010). Graphene nanoplatelets have been shown to have out-performed carbon nanotubes as a reinforced additive at low filler content of $0.1 \%$ (Rafiee et al., 2009).

In a study where graphene/chitosan composite films were fabricated, it was found that graphene significantly increased the modulus of chitosan at very low content, between 0.1 to $0.3 \%$, as seen in Figure 6 . The composites showed good biocompatibility for L929 cells, as confirmed by in vitro MTT assays(Fan et al., 2010). 


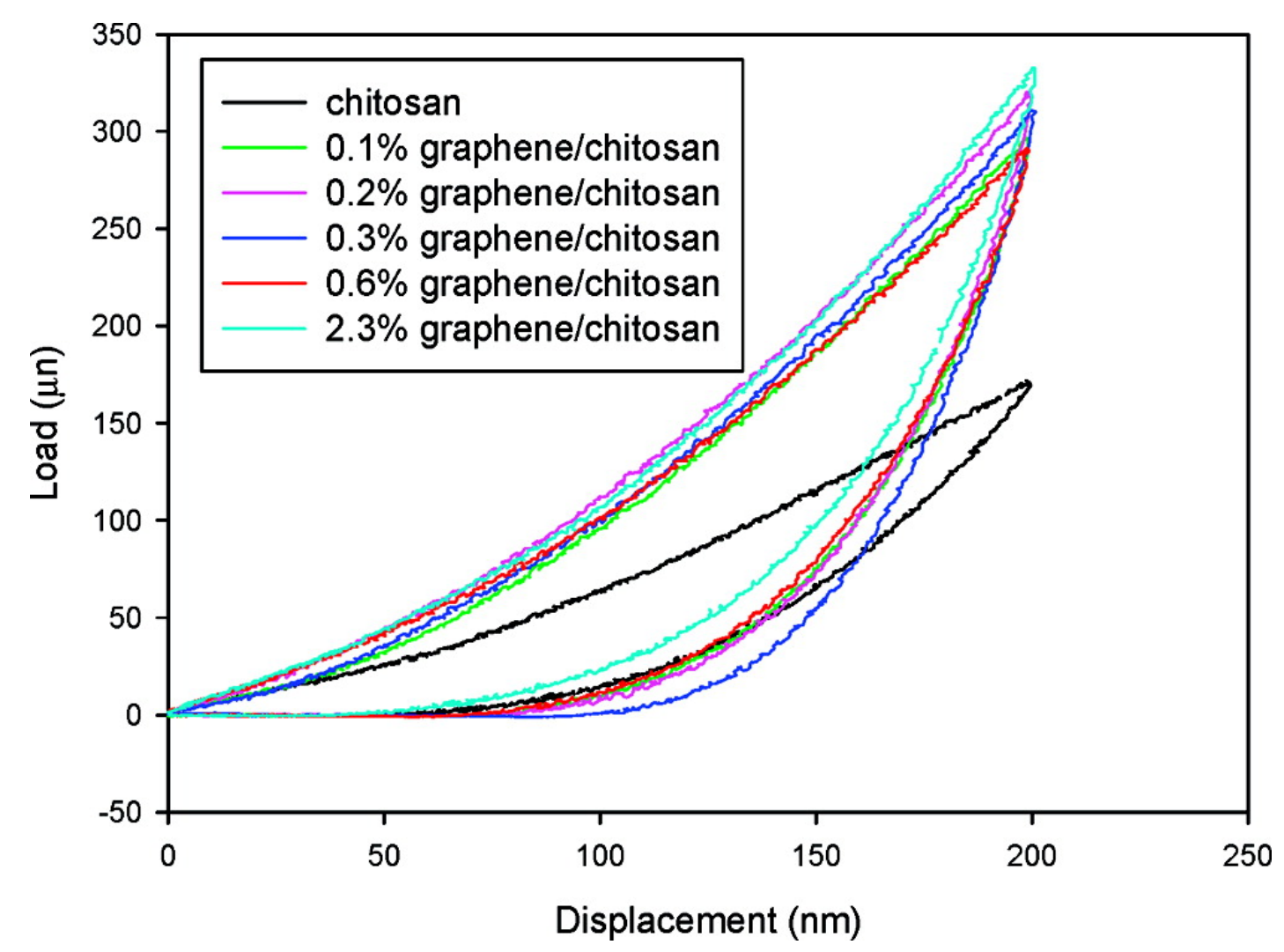

Figure 6: Load vs displacement curves of graphene/chitosan composites with different amounts of graphene. (Fan et al., 2010)

\section{ECM in Heart Valves}

Porcine small intestinal submucosa (SIS) is an acellular matrix from the jejunum; it is commonly used as a xenograft material. SIS has shown to be biocompatible and infection resistant, possess predictable mechanical properties prior to implantation. It induces tissue-specific remodeling responses in the organ or tissue into which it is placed rather than nonspecific scar tissue (Badylak et al., 1995).

Porcine SIS has been shown to replace mature pulmonary valve leaflets in pigs (Matheny, Hutchison, Dryden, Michael, \& Shaar, 2000). Histopathological analysis of the explanted leaflets revealed progressive replacement with fibrous connective tissue and 
microvasculature similar to mature host tissue. There was also a progression of endothelialization of all the substitute leaflet surfaces with time.

Another study investigated the placement of a percutaneous low-profile prosthetic SIS valve in the pulmonary position in 12 female pigs (Ruiz et al., 2005). Within 1 month, the surface was covered by endothelium, and fibroblasts had invaded the interior, as seen in Figure 7. Over the following months, the valve remodeled without apparent graft rejection.

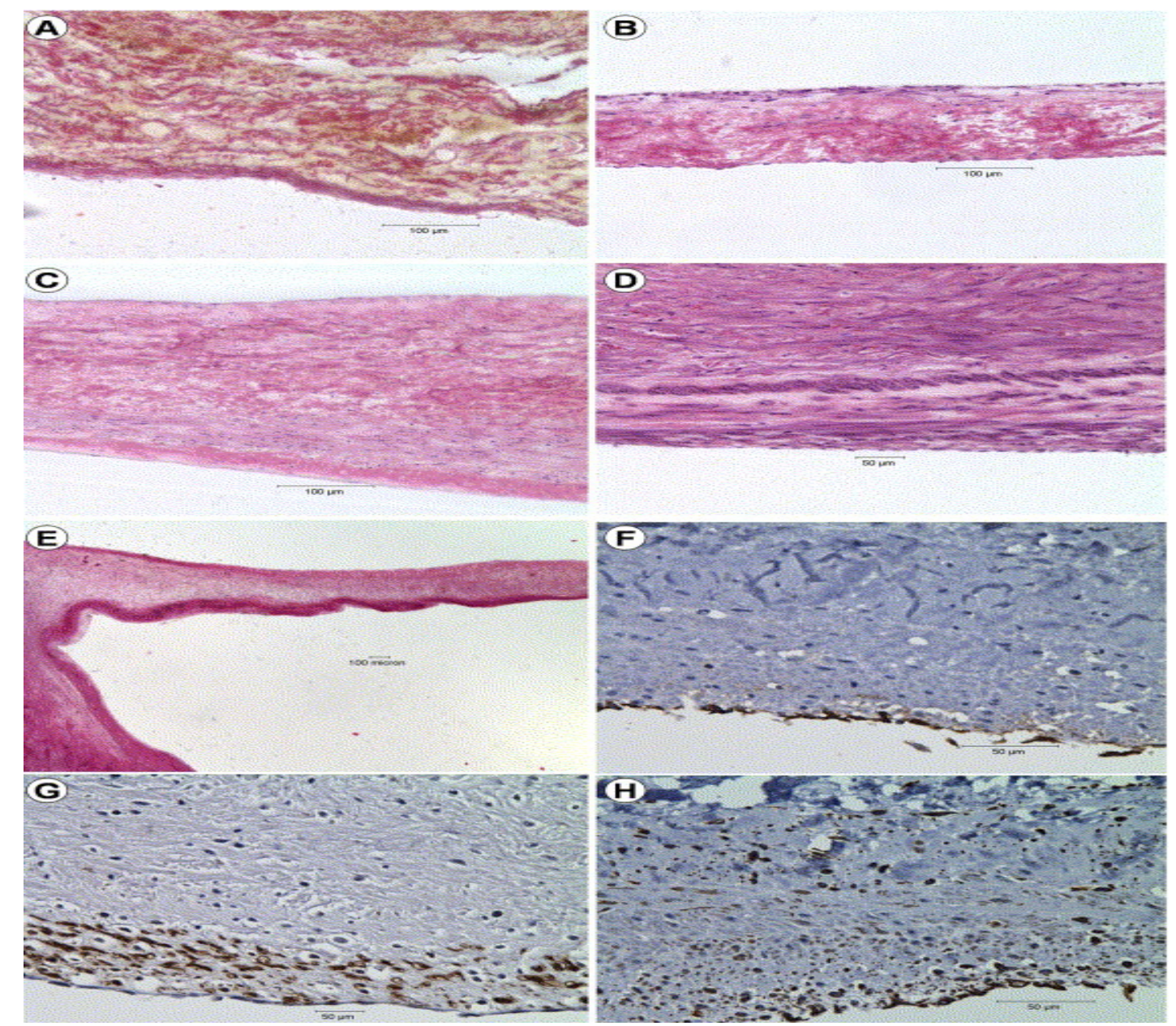

Figure 7: A, SIS 1 day after implantation, hematoxylin and eosin staining. B, 3 months after implantation. C, 6 months after implantation. D, 12 Months after implantation. E, 
Native valve. F-H, SIS Valve 12 months after implantation with antibody staining. F, subendothelial von Willebrand factor VIII. G, interstitial smooth muscle cells. $H$, connective tissue vimentin. (Ruiz et al., 2005). 


\section{Chapter 4 AIM 1: Graphene Reinforced Silicone}

Heart Valve disease is a prevalent clinical problem in the United States. Current options for heart valve replacement include mechanical valves, homograft, and bio-prosthetic valves. Patients with mechanical heart valves however have to take lifelong anticoagulants to prevent risk of thrombus. The down side to these valves is a high risk for fibrosis, calcification, degeneration, and immunogenic complications that may lead to failure in the valve.

Elastomers such as silicone have previously been used to create prosthetic heart valves due to their similarity to native tissue, but are still prone to early structural failure including leaflet tearing. We have incorporated graphene nanoplatelets into the silicone matrix materials. The following study is presented as published in the Journal of Long Term Effects of Medical Implants (Lordeus et al., 2015).

\section{Introduction}

Heart valve disease is characterized by the inability of native heart valves to continue facilitating adequate forward blood flow from the myocardium. When one of the heart valves fail, it can be replaced with an artificial heart valve. Current options for heart valve replacement include: mechanical valves, homograft, and bio-prosthetic valves. Mechanical valves, such as the bi-leaflet and tilting disk designs are often recommended for their durability. Patients with mechanical heart valves however have a substantial risk of systemic thrombotic occlusion(Jamieson, 1993). This is largely due to non-physiologic surfaces and flow abnormalities created by the mechanical valves. Additionally, the patients require lifelong anticoagulant therapy to counteract the thrombus(John \& Liao, 
2013). Anticoagulant use is contraindicated in some heart valve patient sub-sections, such as in pregnant women or women who may decide to have children later in life, because of bleeding complications as well as risk of embryopathy and spontaneous abortions(Chan W, Anand S, \& Ginsberg JS, 2000). On the other hand, homografts and bio-prosthetic tissue valves possess the advantage of not requiring chronic anticoagulant therapy(Grunkemeier \& Rahimtoola, 1990). However these valves are very prone to fibrosis, calcification, degeneration, and immunogenic complications that can lead to early failure(Sacks \& Schoen, 2002). While mechanical, homograft and bio-prosthetic valves have been used in patients for over 50 years and have made significant improvements in patient morbidity, there is still a distinct need to overcome their limitations as evidenced by the ten-year mortality rate following valve replacement, which ranges from 30 to 55\%(Edmunds et al., 1997).

Emerging, elastomer heart valves have been shown to be able to better re-create the flow physics of native heart valves compared to mechanical valves, resulting in preferable hemodynamic responses(Ramaswamy et al., 2013). They can be tailored to mimic the mechanical properties of native tissue to withstand the coupled, flexural, tensile and fluid-induced stresses, while remaining biocompatible and recapitulating native valve motion. Such valves are likely to be suitable for straightforward massproduced in different sizes, while remaining cost effective. Research in the use of polymer materials for the fabrication of tri-leaflet valves has been ongoing for over 50 years, but has faced substantial hurdles in the facilitation of adequate valve durability. However, new methods in manufacturing and reinforcement of polymer materials have resurrected the appeal of polymer materials for heart valve prosthesis application. One 
such material that has found renewed interest is silicone. Unfortunately, silicone is prone to structural failure which drastically limits its applicability for heart valve prosthetics(Roe et al., 1966). Here, we proposed that silicone can be reinforced with graphene nanoplatelets (GNPs) to promote its strength and durability for subsequent valve prostheses development. Graphene is known for its high-strength(Lee et al., 2008). Human cells also exhibit a minimal cytotoxic response to graphene(Santos et al., 2012). Our primary objective therefore was to characterize the response of silicone substrates to static and cyclical loading conditions with and without graphene reinforcement and, in addition, to assess whether the graphene-silicone composites had altered cytotoxicity and platelet adhesion properties relative to the silicone substrate alone.

\section{Methods}

Composite Material Fabrication

Four samples were created, one sample served as the control, which was prepared without graphene, and the other three had final concentrations of 250mg, $75 \mathrm{mg}$, and 25 mg of graphene per liter of uncured silicone. GNP (XG Sciences Inc., Lansing, MI) with 6-8 $\mathrm{nm}$ thickness, $120-150 \mathrm{~m}^{2} / \mathrm{g}$ surface area, and average particle diameters of $5 \mu \mathrm{m}$ were used. The graphene was mixed in acetone (Fisher Scientific, Pittsburg, PA) and allowed to disperse in a sonication bath for 1 hour. The graphene-acetone solution was then added to the base of the 2 part silicone kit (NuSil, Carpinteria, CA) and placed in a vacuum for 15 minutes. The activator was added to the base; then the mixture was spread evenly on a smooth non-stick surface and placed back in the vacuum for an additional 30 minutes, for removal of air bubbles. The samples were finally allowed to cure for at least 24 hours before use. 
Mechanical Testing

Static loading:

Mechanical test samples ( $n=3$ /group) were cut into strips approximately $15 \times 6 \times 0.25$ (mm) from the fabricated bulk materials. Uni-axial tensile testing was carried out (Electroforce 3200 test instrument, Bose Corporation, Eden Prairie, MN) using a $1000 \mathrm{~g}$ load cell and a maximum crosshead movement of 11 at a displacement rate of $0.1 \mathrm{~mm} / \mathrm{s}$, with an initial length of $10 \mathrm{~mm}$. In addition, the testing was conducted while the samples were immersed in a water bath filled with $8 \mathrm{~g} / \mathrm{L}$ of saline solution held at $37^{\circ} \mathrm{C}$, to mimic in vivo environmental conditions (Figure 8).

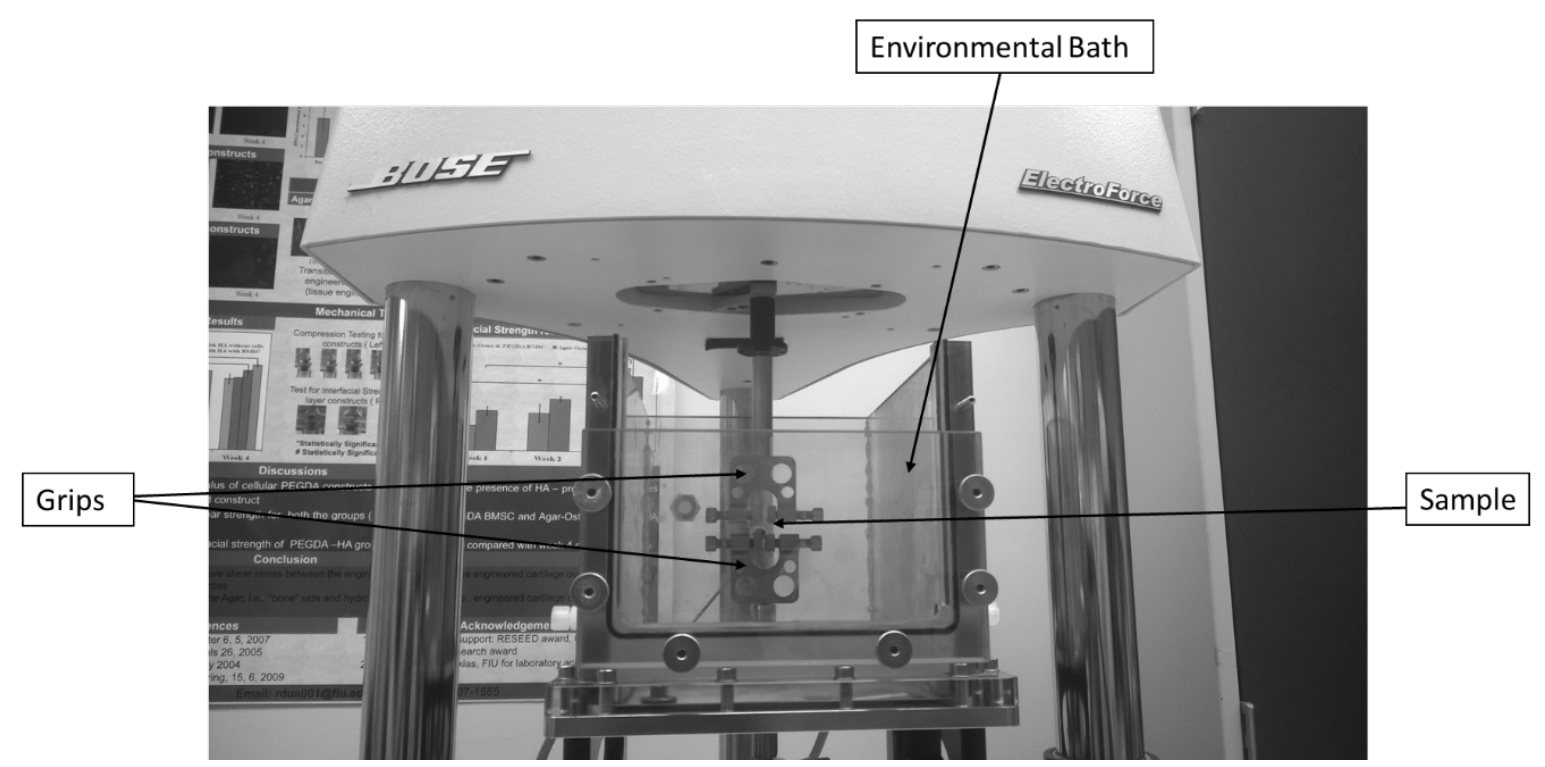

Figure 8: Set up for tensile testing showing the specimen grips and the test conditions, including an envi-ronmental bath filled with $8 \mathrm{~g} / \mathrm{L}$ saline solution (Bose Electroforce system, Eden Prairie, MN). The temperature of the saline bath was maintained at 37oC during testing.

Cyclic loading:

Fatigue properties of the samples ( $n=3$ /group) were subsequently determined (Electroforce 3200, Bose Corporation). Original sample dimensions were $~ 15$ x 6 x 0.25 
$(\mathrm{mm})$. As in the case of static testing, samples were again immersed in the saline bath held at $37^{\circ} \mathrm{C}$.

At a frequency of $0.05 \mathrm{~Hz}$, the samples were cyclically stretched to $10 \mathrm{~mm}$ until failure which was evidenced by sample breakage.

\section{Cell Cytotoxicity}

\section{$\underline{\text { Cell Culture }}$}

Rat Adrenal Medulla Endothelial Cells (RAMECs) (Cellbiologics, Chicago, IL) were seeded onto T-75 flasks (Fisher Scientific). The cells were cultured in the RAMECsupporting endothelial cell media (Sigma-Aldrich, St. Louis, MO) until passage three (3). Once the cells were $90 \%$ confluent, they were trypsinzed from the flask using trypsin (Fisher Scientific). The trypsinzed solution was then centrifuged for 5 minutes at $1700 \mathrm{~g}$. Furthermore, after centrifugation, the supernatant was removed and the pellet of cells obtained was suspended in fresh media. Cells were counted using a haemocytometer and desired quantity of cells were subsequently used for Cell Viability and cell proliferation assays.

\section{Cell Viability}

To study the viability of RAMECs seeded on the silicone and silicone-graphene samples, live mitochondrial and nuclear imaging of cells was performed (Live Mitochondrial and Nuclear Labeling Kit, Invitrogen, Carlsbad, Ca) after 24 hours of cell culture. The samples seeded with the RAMECs were incubated in 200nM MitoTracker Red (mitochondrial staining) and $5 \mu \mathrm{M}$ Hoechst dye (nuclear staining) in endothelial cell media for 15 minutes at $37^{\circ} \mathrm{C}$. When the labeling procedure was completed, excess 
labeling solution was removed by washing with PBS twice. The sample surfaces were subsequently observed under a fluorescence microscope (Olympus IX 81).

\section{Cell Proliferation Assay}

Cell proliferation on the silicone-graphene samples were determined using the sulforhodamine B (SRB) Viability/Cytotoxity Assay Kit (Vitro Vivo Biotechnology, Rockville, MD) which is based on the colorimeteric measurement of viable cellular protein. RAMECs were seeded on the silicone and silicone-graphene surfaces (5mm X $5 \mathrm{~mm}$ ) with a cell density of $10^{5}$ cells/mL. An SRB assay was performed on day 1, day 3 and day 7 (3 samples/group/time-point). In brief, cells were bound to the bottom of the silicone and silicone-graphene substrates using trichloroacetic acid (Vitro Vivo Biotechnology) which served as the fixative. Next the cells were stained using sulforhodamine B dye (Vitro Vivo Biotechnology). The unbounded dye was then removed using $1 \%$ acetic acid (Fisher Scientific). The dye bounded to the cellular protein was extracted using 10mM Trizma (Vitro Vivo Biotechnology) base and the absorbance was measured at a wavelength of 565nm using a micro-plate reader (Biotek Instruments Inc., Winooski, Vermont).

Platelet Adhesion Characteristics

Silicone and silicone-graphene composite samples were cut into $1 \mathrm{~cm} \mathrm{x} 1 \mathrm{~cm}$ squares. Freshly collected whole porcine blood (1L, Mary's Ranch Inc, Miami, FL) was subsequently mixed with $667 \mathrm{~mL}$ of mepacrine dye (Quinacrine Dihydrochloride, Fisher Scientific) and $300 \mathrm{~mL}$ of sodium citrate (Fisher Scientific) anti-coagulant. The samples were then positioned into a custom blood flow loop available in our laboratory. The flow loop was initially cleansed with deionized water for approximately 5 minutes, then 
washed with $1 \mathrm{x}$ phosphate buffered solution (PBS, Fisher Scientific) for approximately 5 minutes. The loop subsequently perfused the blood mixture for 35 minutes at a flow rate of $679 \mathrm{~mL} / \mathrm{min}$. The samples were removed and rinsed with PBS, examined under the microscope, and subsequently analyzed (ImageJ Software, National Institutes of Health/NIH, Bethesda, MD) to quantify the number of platelets adhered to each of the material surfaces.

Statistical Analysis

A one-way ANOVA (SPSS, IBM, Armonk, NY) was executed for all statistics conducted in this study. When the analysis yielded a significant difference, a Dunnet post-hoc test was performed to assess the significance of the graphene treated-groups relative to the control (silicone-only samples). In all evaluations, a statistically significant difference between groups was reported when $\mathrm{p}<0.05$.

\section{Results}

Gross Morphology

Microscopic visualization of the graphene-silicone samples revealed a randomized distribution of dark graphene particles (Figure 9). Some of the particles appeared to have aggregated in certain regions of the specimens. An increased presence of graphene particles was clearly observed at the highest graphene concentration $(250 \mathrm{mg} / \mathrm{L})$ utilized, compared to the other groups $(0,25$ and $75 \mathrm{mg} / \mathrm{L})$. 

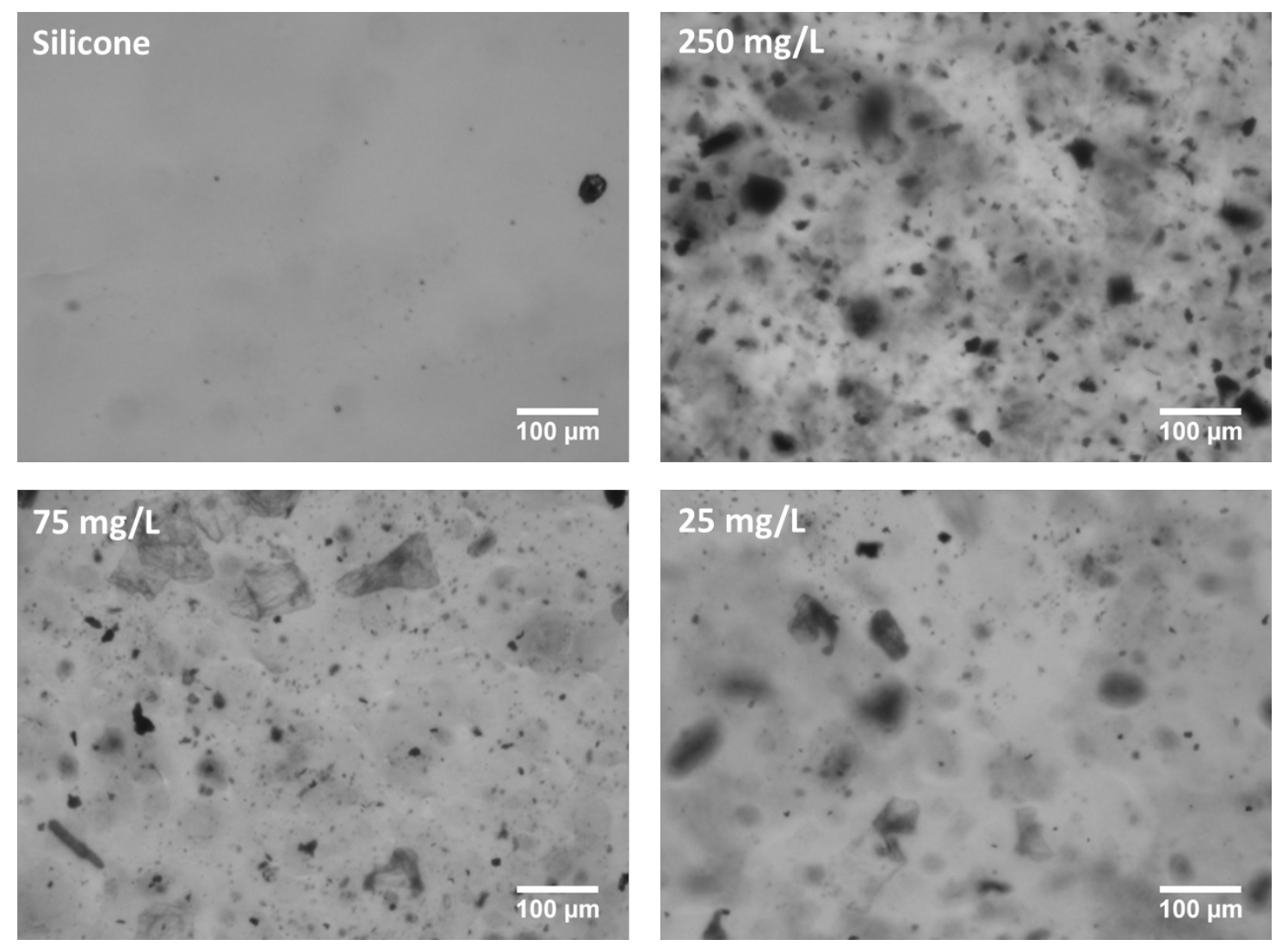

Figure 9: Silicone-graphene material: (a) control containing only silicone. (b) $250 \mathrm{mg}$ GNP, (c) 75 mg GNP, and (d) 25 mg GNP of graphene per liter of uncured silicone.

\section{Mechanical Testing}

Static tensile testing revealed a similar stress-strain behavior (Figure 10A) for all groups tested. The control sample had a Young's modulus of $0.70 \mathrm{MPa}$; the samples containing 250mg, $75 \mathrm{mg}$, and 25mg of graphene per liter of uncured silicone had a Young's modulus of $0.85 \mathrm{MPa}$, 0.67 $\mathrm{MPa}$, and 0.79 $\mathrm{MPa}$, respectively. On the other hand, when a cyclic flexural load was applied $(0.05 \mathrm{~Hz})$, the group with the highest concentration of graphene (250 mg/L) was able to maintain its structural integrity for a significantly longer duration ( $<<0.05$; Figure 10B). While the failure stresses of the silicone-only and GNP-reinforced (250 mg/mL) were comparable in magnitude ( $0.9-1$ MPa range; Figure 10C), the silicone specimens on average lasted 533 cycles compared to 1171 
cycles for the GNP-reinforced silicone composites (Figure 10B). The edges of the samples that failed were inspected utilizing bright field microscopy (Figure 10C). The graphene-containing specimens clearly possessed regions of GNP aggregates dispersed throughout the material, whereas in the silicone-only specimens, a few air bubbles were observed (Fig. 3C); air bubbles were not apparent in the GNP-reinforced silicone samples. 


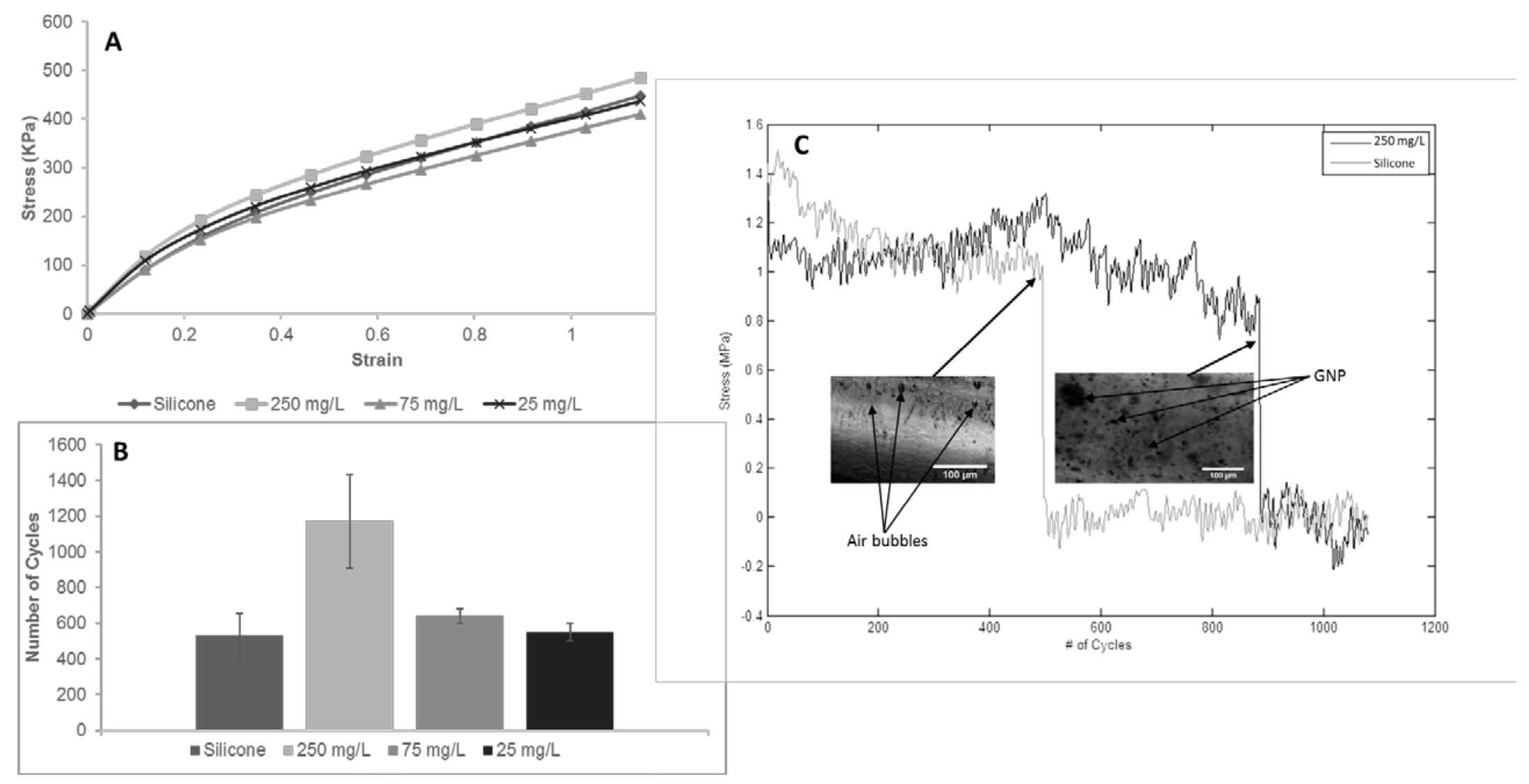

Figure 10: A) Mean stress-strain curve of silicone-graphene material ( $n=3$ specimens/group). B) Mean numbers of cyclic stretch withstood by the samples before specimen failure ( $n=3$ specimens/group). Note that the samples were cyclically stretched from rest to a maximum of $600 \%$ strain at a frequency of $0.05 \mathrm{~Hz}$ until the specimen broke. C) Stress versus number of cycles plot for silicone-only and silicone-GNP (250 mg/mL). The sudden drop in stress demonstrates the point at which the specimen broke. The plot also shows a corresponding view of the cross-section of the edge where breakage occurred. A few small air bubbles were unavoidably present in the silicone-only samples. Introduction of GNP in the silicone matrix permitted an opportunity to serve as a filler material, thereby eliminating the few void spaces within the substrate. 


\section{Cytotoxicity}

Viability verification demonstrated robust mitochondrial staining in the silicone-only as well as in all the GNP-silicone groups (Figure 11A), indicating that the RAMECs were alive and metabolically active after 24 hours of direct physical cell contact with the material surfaces.

Positive cell proliferation occurred in all groups tested (Figure 11B). Compared to cell numbers at day 1, a percentage increase in the relative survivability of RAMECs at day 7 was found as follows: silicone-only: 406\%, $250 \mathrm{mg} / \mathrm{L}$ GNP-silicone: 762\%, $75 \mathrm{mg} / \mathrm{L}$ GNP-silicone: 692\% and 25 mg/L GNP-silicone: 210\%.

A
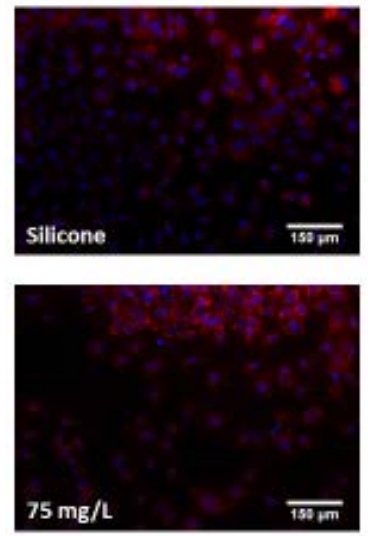
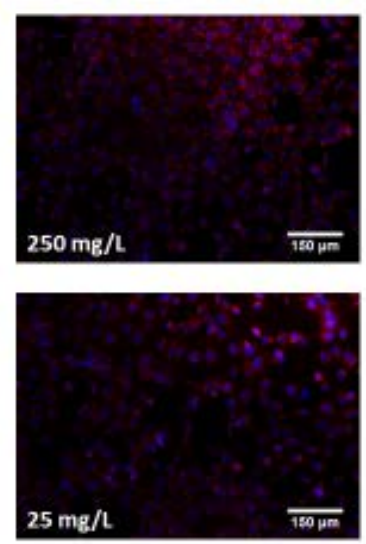

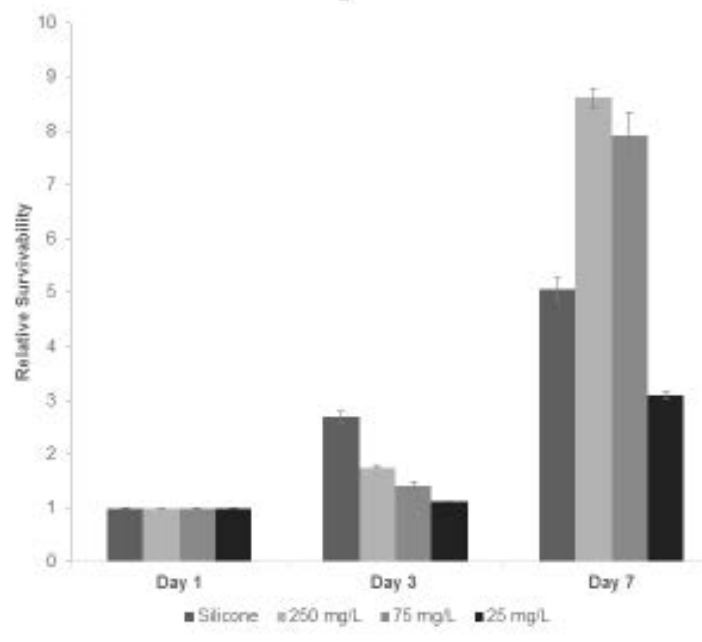

Figure 11: For the silicone-only (control) and silicone-GNP materials (25, 75 and 250 $\mathrm{mg} / \mathrm{mL}$ ), A) Fluorescence images showing cell viability after 24 hours or culture; red color indicates mitochondrial staining and blue color is a counterstain of the nucleus. GNP incorporation appeared to have no adverse effect on cell viability relative to the controls since all groups demonstrated robust metabolic activity as shown by the large degree of positive mitochondrial staining. B) Relative survivability of RAMECs after 1, 3, and 7 days $(n=3)$. All groups demonstrated positive proliferation over 1 week with the 
largest increased observed in the group containing $250 \mathrm{mg} / \mathrm{ml}$ of GNPs within the silicone matrix.

\section{Platelet Adhesion}

Porcine whole blood flow exposure across the samples revealed no significant differences found ( $p>0.05)$ in the number of adhered platelets to the surface of the materials, between any of the groups tested, i.e., GNP-Silicone: $250 \mathrm{mg} / \mathrm{L}, 75 \mathrm{mg} / \mathrm{L}, 25 \mathrm{mg} / \mathrm{L}$ and Silicone -only; (Figure 12).

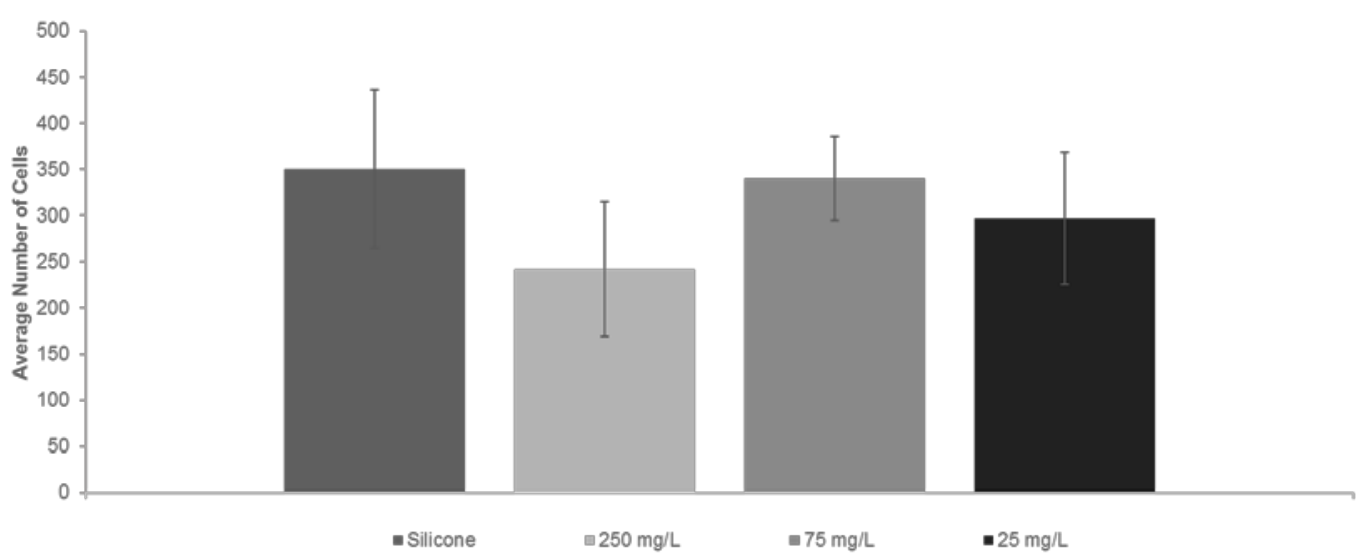

Figure 12: Mean number of platelets on sample surfaces after 35 minutes of exposure to whole blood flow ( $n=2$ samples/group). Porcine blood was used and perfused across the specimen surfaces at a flow rate of $679 \mathrm{~mL} / \mathrm{min}$. The groups tested comprised of siliconeonly, and GNP-silicone composites with the following densities of GNP: $250 \mathrm{mg}, 75 \mathrm{mg}$, and $25 \mathrm{mg}$ of graphene per liter of uncured silicone

\section{DISCUSSION}

Prosthetic valve technologies to replace diseased heart valves represents a mature technology with excellent prognosis for individuals otherwise in good health e.g. most mechanical valves are functional for 20 to 30 years(Blot, 2005; Gott, Alejo, \& Cameron, 2003). However, prosthetic valves are not without distinct limitations, many of which are materials-dependent. For example, the artificial materials that are used to assemble 
mechanical valves are still predisposed to clots and thus require lifelong anti-coagulant therapy; meanwhile bio-prosthetic valves consisting of xenograft, fixed-tissues deform similar to native valve leaflets but tend to fail prematurely due to calcification, structural breakdown and leaflet tearing. Additionally, many older patents ( $\geq 70$ years) cannot be treated for a valve replacement via a traditional route because of mortality risks associated with open- heart surgery. We note that $\sim 50-60 \%$ of patients with replacement valves either need a re-operation or die within ten years of valve implantation(A. Wang \& Bashore, 2009). For this reason, there is a move towards less invasive strategies for valve replacement such as percutaneous valve approaches, which at the moment is only considered in patients at high-risk for open heart surgery and which currently only utilizes pericardium tissue valves. Further advancement of percutaneous valve technologies is also likely to require the development of new valve prosthetics. Clearly, the development of new prosthetic valves is necessary despite the efficacy of current state-of-the-art heart valve implants.

Previously, we reported on the functionality of a novel silicone valve prosthesis(Ramaswamy et al., 2013). This polymer valve was manufactured using a proprietary manufacturing technique from a single silicone piece, thereby eliminating potential weak zones along seam lines that would be created when assembling multiple pieces. Hydrodynamically, the silicone valve exhibited less energy losses and regurgitation volumes compared to bi-leaflet mechanical valves(Ramaswamy et al., 2013). However, silicone is an inherently weak material and additional materials processing is necessary to enhance the valve's durability. To achieve this task, we incorporated GNPs into the silicone matrix. 
GNPs presented themselves as dark aggregates within the silicone substrate (Fig. 2). These dark regions were noticeably more common in specimens reinforced with 250 $\mathrm{mg} / \mathrm{L}$ of GNPs in comparison to the smaller concentrations ( 25 and $75 \mathrm{mg} / \mathrm{L}$ ). There was a propensity for GNPs to clump into various-sized clusters that were in the order of up to $\sim 50 \mu \mathrm{m}$. Interestingly the cytotoxic properties (Fig. 4) and hemocompatibility (Fig. 5) of silicone remained unaltered ( $p>0.05)$ after inclusion of GNPs even at the relatively higher concentration of $250 \mathrm{mg} / \mathrm{L}$. On the contrary, the relative survivability of the cells was augmented by $762 \%$ which demonstrated significantly higher cell proliferation ( $\mathrm{p}<$ 0.05) compared to the silicone-only controls, whose 1-week percent proliferation was 406\%. These findings indicated that that the surface properties of the GNP-silicone composites did not compromise cell properties, specifically viability and growth.

Mechanically, the GNP-silicone composites exhibited a similar constitutive response in the tensile loading direction compared to the silicone-only controls. The samples were stretched up to a strain of 1 and corresponding stresses at this strain value were found to be within a narrow stress range of 410 to $484 \mathrm{KPA}$ (Fig. 3A). The high distensibility of silicone appeared to dominate during deformation with minimal interaction with the embedded GNPs. We subsequently proceeded to cyclic stretch experiments at a low frequency $(0.05 \mathrm{~Hz})$ and continued the testing until sample failure. Ironically, GNP incorporation to the silicone matrix at $250 \mathrm{mg} / \mathrm{mL}$ permitted a substantial improvement in the material's response to cyclic stretch (Fig 3B). When the faces of the broken specimen edges were examined, there was evidence of a few air bubbles or voids within the control samples whereas these were absent in the GNP-silicone material (Fig. 3C). Similar to the initial morphological examination (Fig. 2), at $250 \mathrm{mg} / \mathrm{mL}$ GNP concentration, the 
silicone substrate was infiltrated with GNP aggregates of various sizes which were found to be smoothly integrated within the matrix. We interpret that beyond a critical density of GNP such as at a concentration of $250 \mathrm{mg} / \mathrm{mL}$, the cyclic stretching of the specimens promoted recruitment of GNPs and interaction with the bulk silicone material. In so doing, the GNP-silicone (250 mg/mL) specimen failure did not occur until an additional 638 cycles later (Fig. 3B) and was thus found to be significantly more durable than silicone-alone $(\mathrm{p}<0.05)$. This improvement in material response to cyclic loads as a result of GNP incorporation is likely to be beneficial for elastomer-based valve prosthesis development, particularly for utility in emerging percutaneous valve systems. However, further confirmation at this stage is still necessary via hydrodynamic functionality assessment of such a prosthesis.

In conclusion, we reinforced silicone with GNPs. The introduction of graphene to silicone utilizing $250 \mathrm{mg} / \mathrm{mL}$ of GNP significantly improved $(\mathrm{p}<0.05)$ the fatigue properties of the elastomer. Silicone can be easily formed into tri-leaflet valve configurations with leaflet dynamics depicting the movement of native heart valves; however the elastomer inherently possesses poor tear strength and lacks durability which has limited its utility for heart valve prosthesis application. Our initial findings here suggest that GNPs can augment the durability of the silicone matrix while still allowing for sufficient distensibility, potentially resembling native valve leaflets. This work provides the foundation for preparing tri-leaflet silicone-graphene heart valves for hydrodynamic functionality testing, which will be the next step in this research. 


\section{Chapter 5 AIM 2: Ecm Valves}

\section{Background}

We have collaborated with cardiac surgeons at Joe DiMaggio Children's Hospital to evaluate a long-term solution for children with heart valve defects. Mechanical valves and bioprosthetics substitutes are problematic for children. There is a lack of appropriate sizes for implants in small children and neonates. As the child grows, the mechanical valve becomes mismatched and will require re-replacement. The child will also require strict anticoagulation therapy to mitigate the lifetime risk of thromboembolic and bleeding complications

Although the bioprosthetics do not require anticoagulation therapy, the tissue is not living and will not grow with the child. The durability of the bioprosthetic in pediatric patients is limited due to the high risk of accelerated structural valve degeneration and early calcification.

The Ross procedure remains achoice for aortic valve replacement in infants and children. However, the operation is a technically demanding procedure and requires the surgeons to operate on and replace both the pulmonary valve and the aortic valve.

The extracellular matrix (ECM) material that we are investigating in this study has the potential to recruit cells from the surrounding area to become living tissue. The ECM derives from the porcine small intestinal submucosa. If the valve leaflets could be replaced with such a tissue, the whole valve may be able to grow with the patient (via in vivo tissue remodeling processes) and not require anticoagulation therapy, while the maintaining good durability and hydrodynamic performance. 
The surgeons have already implanted these leaflets into pediatric patents in compassionate care situations and have shown promising results. In essence the valves have thus far functioned flawlessly (at the time of this thesis, for $\sim 1$ year after valve implantation). In this study, with are characterizing the acute in vitro performance of these valves in the aortic position.

\section{Method}

Valves

Fresh porcine hearts were harvested from a USDA approved slaughterhouse (Mary's Ranch Inc, Miami, FL) and the aortic root were isolated using a scalpel. The aortic valve and the aorta conduit were separated and stored in PBS solution mixed with a protease inhibitor cocktail (Sigma-Aldrich).

The aortic root and conduit were provided to cardiac surgeons at Joe DiMaggio Children's Hospital to construct the valves. To create the aortic valve, the native leaflets in the aortic root were removed. The ECM (CorMatrix, Roswell, GA) was cut using the pattern from patent 5,716,399 (Figure 13). The ECM material was submerged in saline to hydrate it. The ECM material was then sutured in the aortic root around the annulus and the wall root where the original leaflets met. 


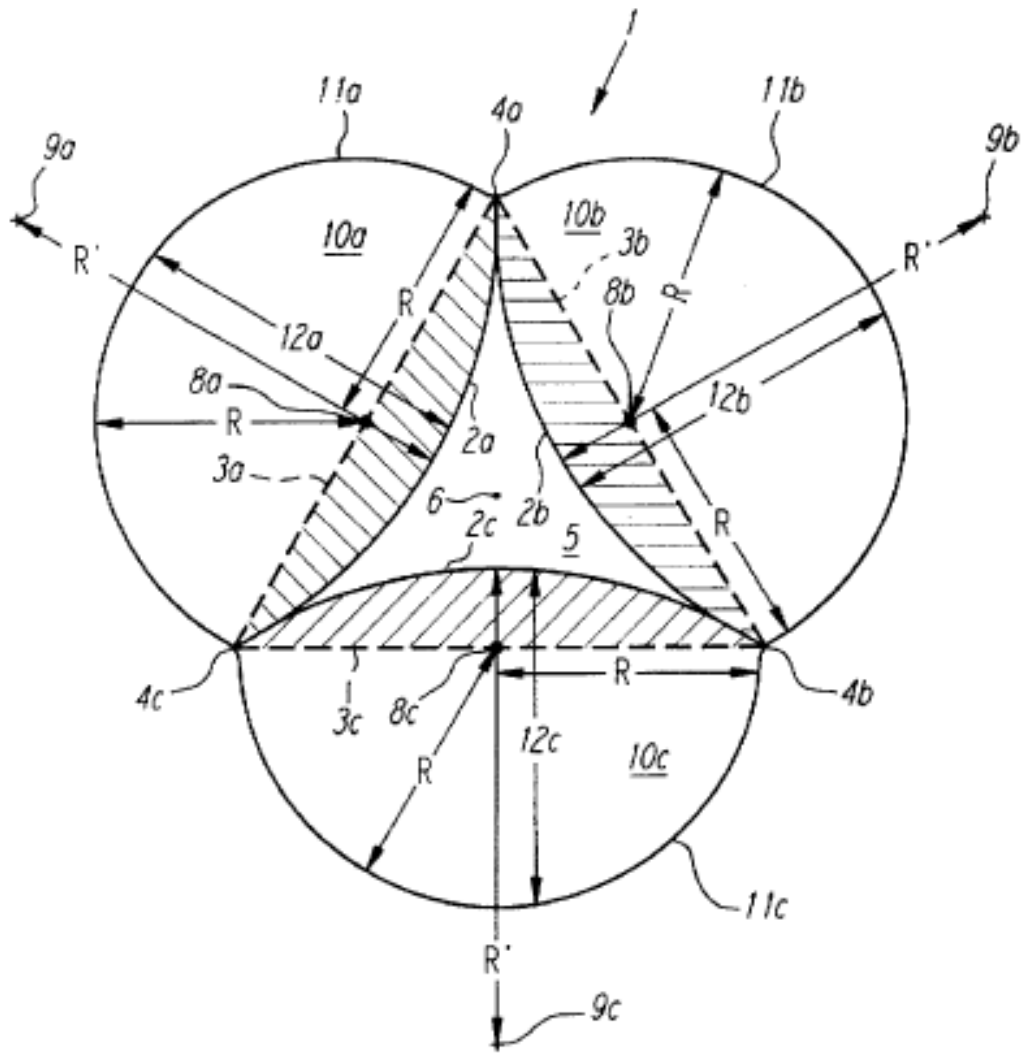

Figure 13: Pattern used for aortic leaflets. (Love, 1998)

Valve Testing

Valve testing was performed using a pulse duplicator (Vivitro Labs, Vancover, Canada), that simulates the left side of the heart (left ventricle and left atrium). The valves were positioned into the base of the valve holders and sutured to the holder around the annulus and sino-tubular junction (STJ) of the valve. The valve holder was then inserted into the pulse duplicator and the system was checked for leaks. Upon verification that the system 
was leak-free, hydrodynamic Evaluation was conducted using the following parameters, (see Table 2).

Table 2: Parameters for hydrodynamic testing

\begin{tabular}{|c|c|}
\hline Parameter & Setting \\
\hline Heart Rate & $70 \mathrm{bpm}$ \\
\hline Flow Waveform & S35 (35\% systolic) \\
\hline Stroke Rate & $80 \mathrm{ml} /$ stroke \\
\hline Testing Fluid & $0.9 \%$ Saline \\
\hline
\end{tabular}

\section{Calculations}

Data was calculated using the following equations (1-3) where $\mathrm{Q}$ is flow (ml/s); $\Delta \mathrm{P}$ is the mean pressure difference(mmHg); $\rho$ is the density of the test fluid $\left(\mathrm{g} / \mathrm{cm}^{3}\right) ; \mathrm{v}$ is the velocity of the fluid; Aaorta is the cross sectional area of the aorta; and SV is the stroke volume. Figure 14 shows a representative flow and pressure waveform used to identify the different pressure and flow points.

$$
\begin{gathered}
Q_{r m s}=\sqrt{\frac{Q_{1}^{2}+Q_{2}^{2}+\cdots+Q_{n}^{2}}{n}} \\
E O A=\frac{Q_{r m s}}{51.6 * \sqrt{\Delta P}} \\
\text { Equation 1 } \\
\text { Energation 2 } \\
\text { Energ Loss }=\left(\frac{\rho * v^{2}}{2}\right) *\left(1-\left(\frac{E O A}{A_{\text {aorta }}}\right)\right)^{2} * S V
\end{gathered}
$$

Equation 3 


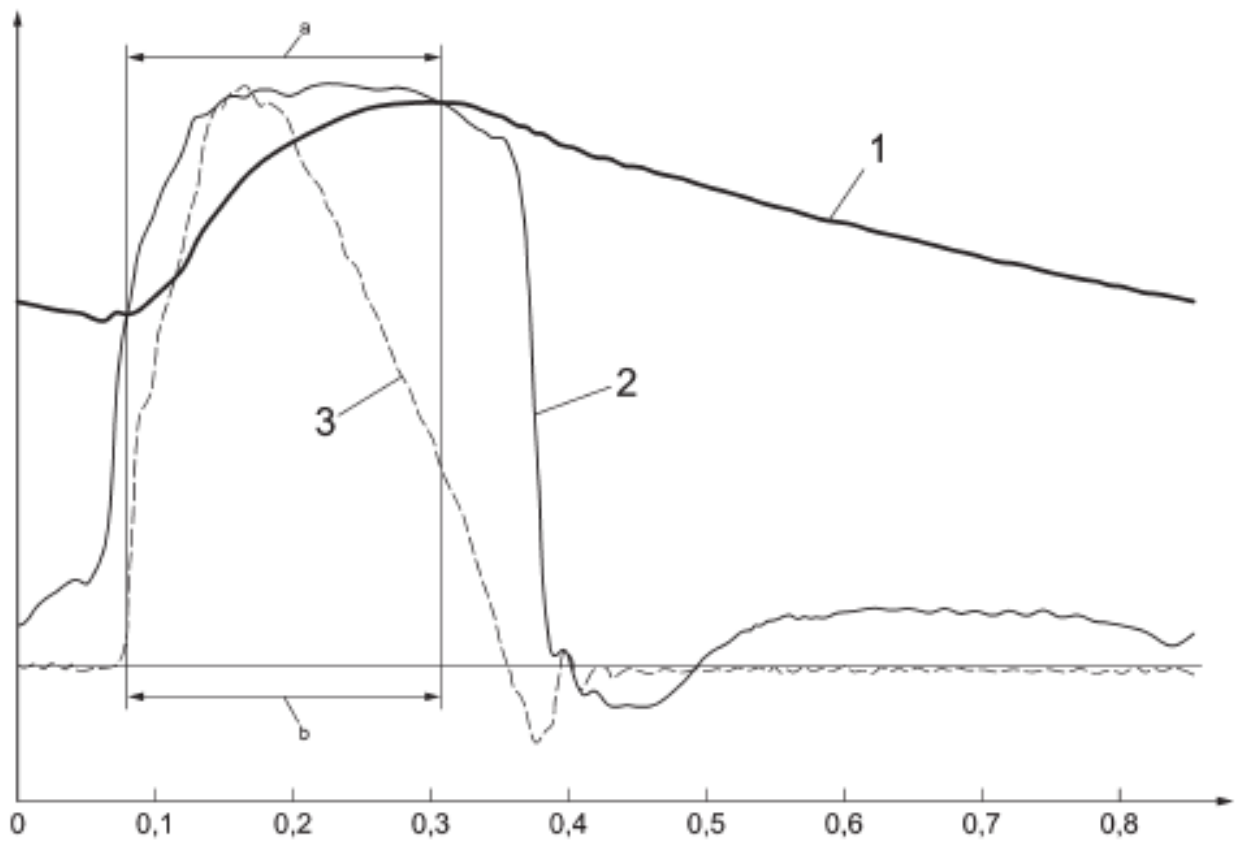

Key title

1 aortic pressure

2 left ventricular pressure

3 aortic flow rate

a Positive pressure range.

b Qrms range.

Figure 14 - schematic representation of the positive pressure period of an aortic forward flow interval from ISO-5840

\section{Results and Discussions}

Hydrodynamic testing results showed that the ECM valve preformed very close to the commercially available Medtronic freestyle bio-prosthetic valve. The pressure profiles as seen in Figure 15 are very similar. The aortic pressure profiles during systole (when the valve is fully open and blood is flowing through the aortic valve) are near identical. There were slight differences between ECM and bioprosthetic valve aortic pressure profilesduring diastole, although the overall shape of the pressure curves remained very similar. 


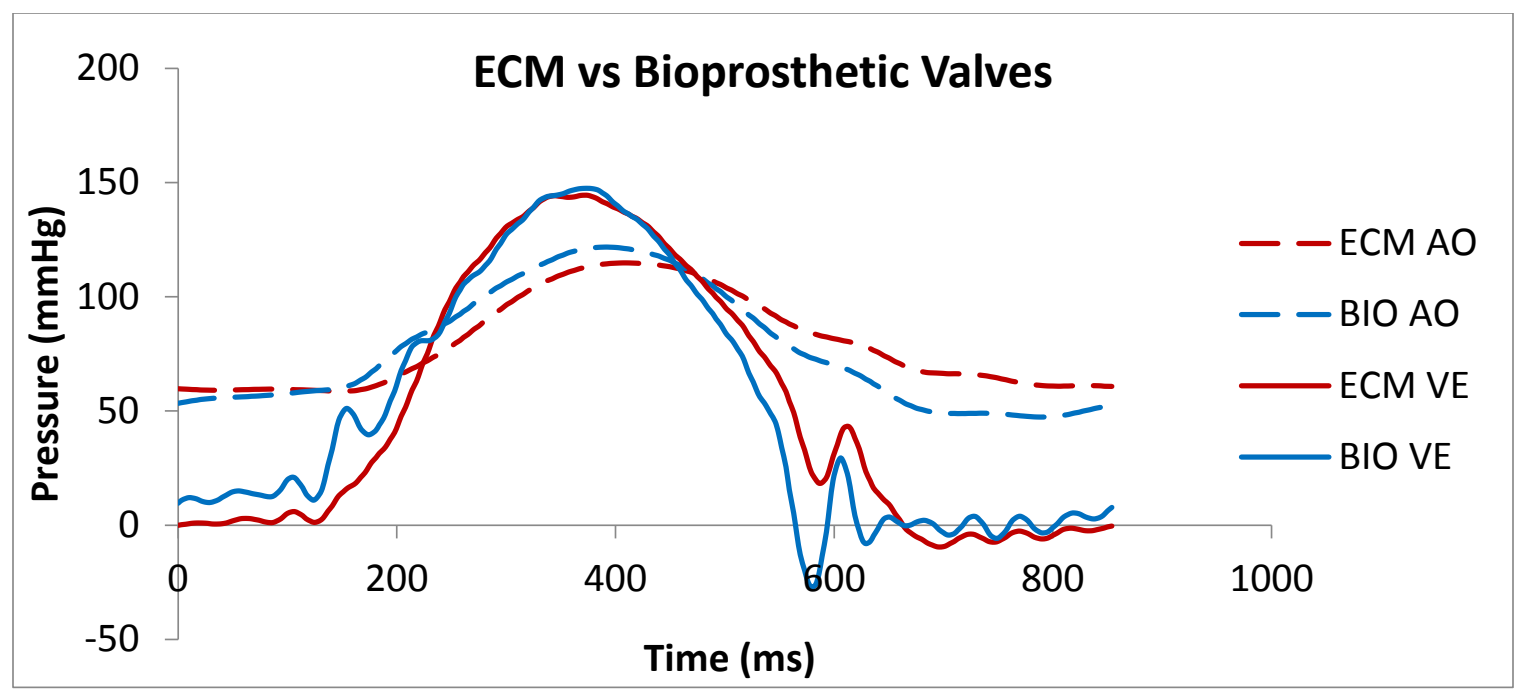

Figure 15- Aortic and Ventricular pressure profiles for the ECM and Medtronic bioprosthetic

The flow profile as seen Figure 16, also shows that the valves performed similarly from a flow standpoint. The bioprosthetic valve did show significantly higher leakage during diastole ( $\mathrm{P}<0.05$ ), but the RMS flow (which is calculated during forward flow) was not found to be significantly different from the ECM valves $(\mathrm{P}>0.05)$. This type of leakage could have occurred as a result of fit mismatches between the bioprosthetic valve and the testing fixture leading to small amounts of paravalvular leakage. 


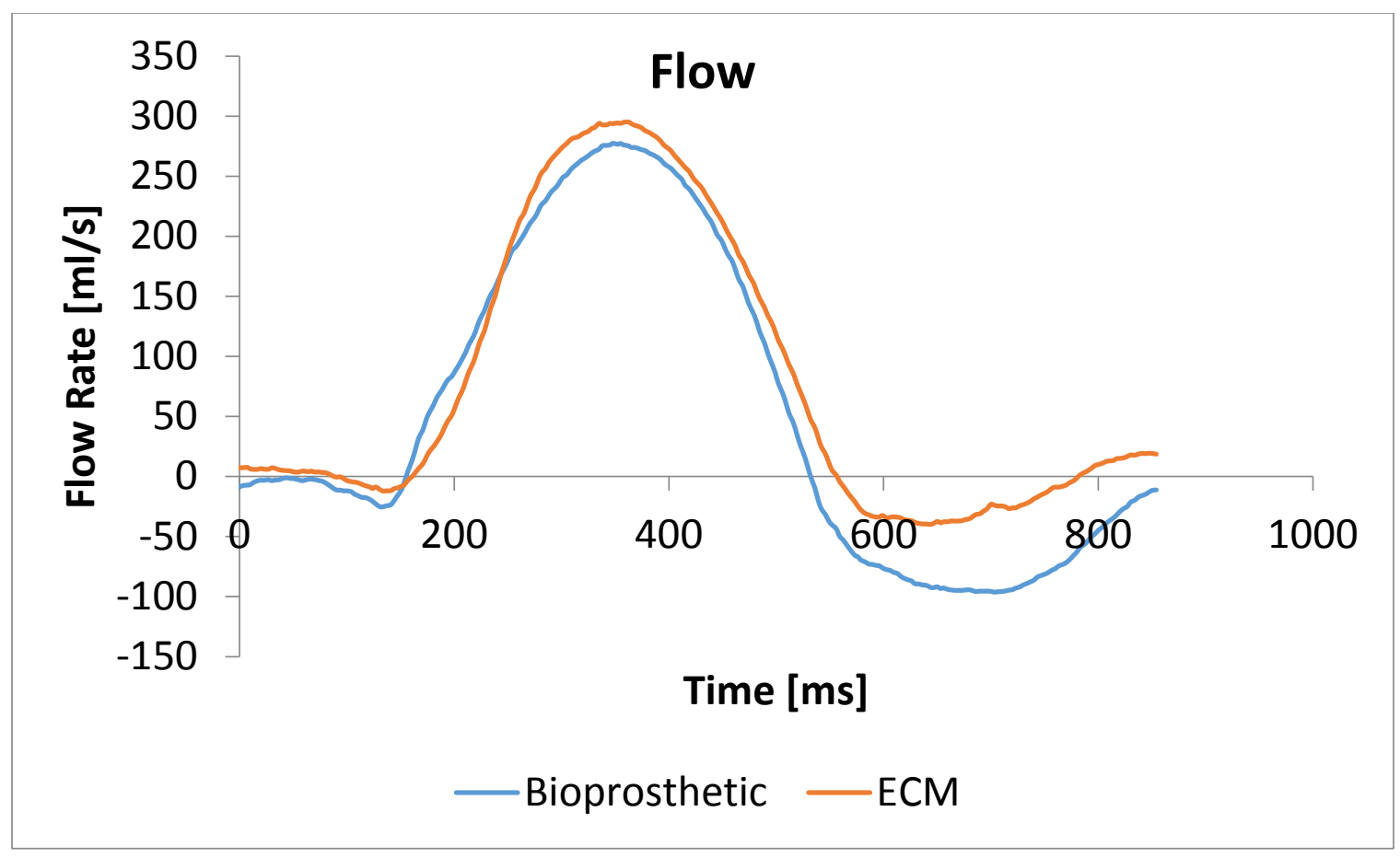

Figure 16- Flow rate of ECM and Medtronic Bioprosthetic valve

The summary of the hydrodynamic testing is shown in Table 3. The mean pressure drop, RMS Flow, and EOA were all close and not statistically significant $(\mathrm{P}>0.05)$ when a nonparametric Mood Median test was performed. The Mood Median test was selected due to the small sample sizes. A traditional t-test was not used since the sample sizes are too small to determine whether the data is normally disturbed. The regurgitation fraction is higher $(\mathrm{p}<0.05)$ for the bioprosthetic valve, mostly likely due to paravalular leakage. The systolic energy loss was significantly $(\mathrm{p}<0.05)$ higher for the ECM valve, and may indicate an area of concern in the long-term for the ECM valve. However, more testing and verification with clinical results are needed to confirm this finding. 
Table 3 - Summary of hydrodynamic results. * denote statistically significant $(P<0.05)$

\begin{tabular}{|c|c|c|c|c|c|}
\hline Aortic Valves & $\begin{array}{c}\Delta \mathbf{P} \\
{[\mathrm{mmHg}]}\end{array}$ & $\mathbf{Q}_{\mathrm{rms}}[\mathrm{ml} / \mathrm{s}]$ & $\begin{array}{c}\text { EOA } \\
{\left[\mathbf{c m}^{2}\right]}\end{array}$ & $\begin{array}{c}\text { Regurgitation } \\
\text { Fraction } \\
{[\%]^{*}}\end{array}$ & $\begin{array}{c}\text { Systolic } \\
\text { Energy Loss } \\
{[\mathbf{m J}]^{*}}\end{array}$ \\
\hline $\begin{array}{c}\text { PSIS ECM } \\
(\mathbf{n}=3)\end{array}$ & $24.0 \pm 2.4$ & $\begin{array}{c}239.9 \pm \\
44.4\end{array}$ & $\begin{array}{c}0.96 \pm \\
0.21\end{array}$ & $13.8 \pm 9.8$ & $36.4 \pm 19.1$ \\
\hline $\begin{array}{c}\text { Bioprosthetic } \\
(\mathbf{n = 2 )}\end{array}$ & $18.1 \pm 1.9$ & $244.4 \pm 3.6$ & $\begin{array}{c}1.12 \pm \\
0.08\end{array}$ & $51.3 \pm 0.8$ & $2.9 \pm 0.7$ \\
\hline
\end{tabular}

All these results indicate that the valve created with the ECM material performed very similarly to the commercially available Medtronic Freestyle valve. We would expect good performance if these valves are implanted to patients. The hydrodynamic performance of the ECM material combined with its ability to cellularize after implantation suggests that these valves would benefit infants and young patients with critical valve disease, due to the ability to support somatic growth. Of note, the EOA that was calculated for the commercially available bioprosthetic that we tested is within the manufacturer’s product specifications (Del Rizzo \& Abdoh, 1998). Hence this verified the accuracy of our measurements.

\section{Chapter 6 Limitations and Future Studies}

The two aims of my research have investigated different flexible materials for aortic valve applications. The first aim has looked at a novel graphene reinforced silicone material that is more durability than silicone on its own and the second aim deals with a novel use for the ECM material. Both these materials provide some advantages over 
materials currently being used in commercially available products and solve some of their inherent problems. A lot of work still needs to be done to completely understand these materials when used for aortic valve applications.

\section{Graphene Reinforced Silicone}

Aim 1 of this study has shown that graphene is able to reinforce the silicone matrix and improve its durability. This opens the potential for use as a new material for heart valves.

The cyclic fatigue was conducted at a rate of $0.05 \mathrm{~Hz}$ due to limitation of the testing hardware. In physiological conditions, the material would experience of around $1.2 \mathrm{~Hz}$ due to the opening and closing of the heart valve. Even though frequency was much lower than what would be experience by an implanted heart valve, the strains used in the study were many time greater than the strain the heart valve would ever experience.

Further studies are needed to evaluate the graphene reinforced silicone for use as a material for heart valve application. Like native silicone, the material could still be easily manufactured into different shapes. A heart valve could be created using injection molding to predict the hydrodynamic properties and effectiveness of such a valve after implantation. Thin sheets of the silicone graphene material could also be produced and combined with self-explaining nitinol stent to study it's potential for transcatheter applications.

The preliminary studies have shown good biocompatibility and low cytotoxicity. However, further studies are needed to completely characterize the safety of graphenereinforced material. An animal study would be able to show how the surrounding tissue will interact with the material. 


\section{ECM Valves}

The ECM valves have shown good hydrodynamic properties and acute performance after the valve is implanted. The hydrodynamic testing was performed using parameters for an adult. The valves that have been implanted so far have been in children. Also, this study only looked at acute performance of the valve.

The valves still need to be further characterized. Long-term studies need to be conducted to observe how the valve changes over time. Durability of the valve also needs to be assessed. Accelerated wear testing would be able to show how the ECM leaflets would survive hundreds of millions of cycles under pulsatile conditions, i.e. if the valves will remain functional from a structural standpoint, over several years.

Further studies are needed to investigate how the ECM material is being cellularized after it is implanted into the valve, the rate of its degradation and if it does in fact accommodate somatic growth. Longitudinal histological assessment from in vivo studies will need to be conducted to see what type of cells proliferate in the ECM scaffold space, the extent of scaffold degradation and the type of matrix components being expressed extracellularly.

Since the ECM material is already decellularized, it has the potential to act as a tissue engineering scaffold. Cells from the target patient would be taken and used to seed the ECM material to form living tissue and then made into a heart valve. The valve would have living tissue, so it would be much closer to a native valve. Since the tissue is made with the patients one cells, the body would not reject it. The patient would not need to take any immunosuppressant to prevent rejection of the tissue. However whether in vitro 
cell-seeding (e.g. with stem cells) would provide a significant advancement over the acellular ECM material for valve replacement purposes is not known at this time. 


\section{List of References}

Ali, A., Halstead, J. C., Cafferty, F., Sharples, L., Rose, F., Lee, E., ... Tsui, S. (2007). Early Clinical and Hemodynamic Outcomes After Stented and Stentless Aortic Valve Replacement: Results From a Randomized Controlled Trial. The Annals of Thoracic Surgery, 83(6),

2162-2168. http://doi.org/10.1016/j.athoracsur.2007.01.021

Badylak, S. F., Tullius, R., Kokini, K., Shelbourne, K. D., Klootwyk, T., Voytik, S. L., ... Simmons, C. (1995). The use of xenogeneic small intestinal submucosa as a biomaterial for Achille's tendon repair in a dog model. Journal of Biomedical Materials Research, 29(8), 977-985. http://doi.org/10.1002/jbm.820290809

Blot, W. J. (2005). Twenty-Five-Year Experience With the Bjork-Shiley Convexoconcave Heart Valve: A Continuing Clinical Concern. Circulation, 111(21), 2850-2857. http://doi.org/10.1161/CIRCULATIONAHA.104.511659

Bové, T., Belleghem, Y. V., François, K., Caes, F., Overbeke, H. V., \& Nooten, G. V. (2006). Stentless and stented aortic valve replacement in elderly patients: factors affecting midterm clinical and hemodynamical outcome. European Journal of Cardio-Thoracic Surgery, 30(5), 706-715. http://doi.org/10.1016/j.ejcts.2006.07.017

Braunwald, N. S., \& Morrow, A. G. (1965). A LATE EVALUATION OF FLEXIBLE TEFLON PROSTHESES UTILIZED FOR TOTAL AORTIC VALVE REPLACEMENT. POSTOPERATIVE CLINICAL, HEMODYNAMIC, AND PATHOLOGICAL ASSESSMENTS. The Journal of Thoracic and Cardiovascular Surgery, 49, 485-496.

Chan W, Anand S, \& Ginsberg JS. (2000). Anticoagulation of pregnant women with mechanical heart valves: A systematic review of the literature. Archives of Internal Medicine, 160(2), 191-196. http://doi.org/10.1001/archinte.160.2.191

Cohen, G., Christakis, G. T., Joyner, C. D., Morgan, C. D., Tamariz, M., Hanayama, N., ... Goldman, B. S. (2002). Are stentless valves hemodynamically superior to stented valves? A prospective randomized trial. The Annals of Thoracic Surgery, 73(3), 767-778. http://doi.org/10.1016/S0003-4975(01)03338-0

Del Rizzo, D. F., \& Abdoh, A. (1998). Clinical and Hemodynamic Comparison of the Medtronic Freestyle and Toronto SPV Stentless Valves. Journal of Cardiac Surgery, 13(5), 398-407. http://doi.org/10.1111/j.1540-8191.1998.tb01103.x 
Desai, S. S., \& Lodge, A. J. (2009). Surgery of the Tricuspid and Pulmonary Valves. In A. Wang \& T. M. Bashore (Eds.), Valvular Heart Disease (pp. 335-358). Humana Press. Retrieved from http://link.springer.com/chapter/10.1007/978-159745-411-7_15

Dominik, D. J., \& Zacek, D. P. (2010). Surgical Anatomy of the Heart Valves. In Heart Valve Surgery (pp. 21-40). Springer Berlin Heidelberg. Retrieved from http://link.springer.com/chapter/10.1007/978-3-642-12206-4_2

Edmunds, L. H., Mckinlay, S., Anderson, J. M., Callahan, T. H., Chesebro, J. H., Geiser, E. A., ... Didisheim, P. (1997). Directions for improvement of substitute heart valves: National Heart, Lung, and Blood Institute's working group report on heart valves. Journal of Biomedical Materials Research, 38(3), 263-266. http://doi.org/10.1002/(SICI)1097-4636(199723)38:3<263::AIDJBM11>3.0.CO;2-C

Emery, R. W., Krogh, C. C., Arom, K. V., Emery, A. M., Benyo-Albrecht, K., Joyce, L. D., \& Nicoloff, D. M. (2005). The St. Jude Medical Cardiac Valve Prosthesis: A 25-Year Experience With Single Valve Replacement. The Annals of Thoracic Surgery, 79(3), 776-782. http://doi.org/10.1016/j.athoracsur.2004.08.047

Fan, H., Wang, L., Zhao, K., Li, N., Shi, Z., Ge, Z., \& Jin, Z. (2010). Fabrication, Mechanical Properties, and Biocompatibility of Graphene-Reinforced Chitosan Composites. Biomacromolecules, 11(9), 2345-2351. http://doi.org/10.1021/bm100470q

Food and Drug Administration. (2010, January 20). Guidance Documents (Medical Devices and Radiation-Emitting Products) - Draft Guidance for Industry and FDA Staff: Heart Valves - Investigational Device Exemption (IDE) and Premarket Approval (PMA) Applications. Retrieved June 26, 2014, from http://www.fda.gov/medicaldevices/deviceregulationandguidance/guidancedocum ents/ucm193096.htm

Fox, H. W., \& Zisman, W. A. (1950). The spreading of liquids on low energy surfaces. I. polytetrafluoroethylene. Journal of Colloid Science, 5(6), 514-531. http://doi.org/10.1016/0095-8522(50)90044-4

Garcia, D., \& Kadem, L. (2006). What do you mean by aortic valve area: geometric orifice area, effective orifice area, or gorlin area? Journal of Heart Valve Disease, 15(5), 601. 
Gott, V. L., Alejo, D. E., \& Cameron, D. E. (2003). Mechanical heart valves: 50 years of evolution. The Annals of Thoracic Surgery, 76(6), S2230-S2239. http://doi.org/10.1016/j.athoracsur.2003.09.002

Grunkemeier, G. L., \& Rahimtoola, S. H. (1990). Artificial Heart Valves. Annual Review of Medicine, 251-263. http://doi.org/10.1146/annurev.me.41.020190.001343

Hayek, E., Gring, C. N., \& Griffin, B. P. (2005). Mitral valve prolapse. The Lancet, 365(9458), 507-518. http://doi.org/10.1016/S0140-6736(05)17869-6

Hinton, R. B., \& Yutzey, K. E. (2011). Heart Valve Structure and Function in Development and Disease. Annual Review of Physiology, 73(1), 29-46. http://doi.org/10.1146/annurev-physiol-012110-142145

Hoffman, J. I. ., \& Kaplan, S. (2002). The incidence of congenital heart disease. Journal of the American College of Cardiology, 39(12), 1890-1900. http://doi.org/10.1016/S0735-1097(02)01886-7

Jamieson, W. R. E. (1993). Modern Cardiac Valve Devices? Bioprostheses and Mechanical Prostheses: State of the Art. Journal of Cardiac Surgery, 8(1), 89-98. http://doi.org/10.1111/j.1540-8191.1993.tb00580.x

Jin, X. (2002). Do stentless valves make a difference? European Journal of CardioThoracic Surgery, 22(1), 95-100. http://doi.org/10.1016/S1010-7940(02)00195-1

John, R., \& Liao, K. (2013). Heart Valve Disease. In P. A. Iaizzo, R. W. Bianco, A. J. Hill, \& J. D. S. Louis (Eds.), Heart Valves (pp. 121-158). Springer US. Retrieved from http://link.springer.com/chapter/10.1007/978-1-4614-6144-9_6

Kidane, A. G., Burriesci, G., Edirisinghe, M., Ghanbari, H., Bonhoeffer, P., \& Seifalian, A. M. (2009). A novel nanocomposite polymer for development of synthetic heart valve leaflets. Acta Biomaterialia, 5(7), 2409-2417. http://doi.org/10.1016/j.actbio.2009.02.025

Kiraly, R., Yozu, R., Hillegass, D., Harasaki, H., Murabayashi, S., Snow, J., \& Nosé, Y. (1982). Hexsyn Trileaflet Valve: Application to Temporary Blood Pumps. Artificial Organs, 6(2), 190-197. http://doi.org/10.1111/j.15251594.1982.tb04082.x 
Kolff, W. J., \& Yu, L. S. (1989). The return of elastomer valves. The Annals of Thoracic Surgery, 48(3, Supplement), S98-S99. http://doi.org/10.1016/00034975(89)90658-9

Lee, C., Wei, X., Kysar, J. W., \& Hone, J. (2008). Measurement of the Elastic Properties and Intrinsic Strength of Monolayer Graphene. Science, 321(5887), 385-388. http://doi.org/10.1126/science.1157996

Lian, H., Li, S., Liu, K., Xu, L., Wang, K., \& Guo, W. (2011). Study on modified graphene/butyl rubber nanocomposites. I. Preparation and characterization. Polymer Engineering \& Science, 51(11), 2254-2260. http://doi.org/10.1002/pen.21997

Lordeus, M., Estrada, A., Stewart, D., Dua, R., Zhang, C., Agarwal, A., \& Ramaswamy, S. (2015). Graphene nanoplatelet-reinforced silicone for the valvular prosthesis application. Journal of Long-Term Effects of Medical Implants, 25(1-2), 95-103.

Love, J. W. (1998, February 10). Methods of heart valve repair. Retrieved from http://www.google.com/patents/US5716399

Mann, D. L., Zipes, D. P., Libby, P., Bonow, R. O., \& Braunwald, E. (Eds.). (2014). Braunwald's heart disease: a textbook of cardiovascular medicine (Tenth edition). Philadelphia, PA: Elsevier/Saunders.

Matheny, R. G., Hutchison, M. L., Dryden, P. E., Michael, H., \& Shaar, C. J. (2000). Porcine small intestine submucosa as a pulmonary valve leaflet substitute. The Journal of Heart Valve Disease, 9(6), 769-74; discussion 774-5.

Nistal, F., García-Martínez, V., Arbe, E., Fernández, D., Artiñano, A., Mazorra, F., \& Gallo, I. (1990). In vivo experimental assessment of polytetrafluoroethylene trileaflet heart valve prosthesis. The Journal of Thoracic and Cardiovascular Surgery, 99(6), 1074-1081.

O’Brien, M. F., Harrocks, S., Stafford, E. G., Gardner, M. A., Pohlner, P. G., Tesar, P. J., \& Stephens, F. (2001). The homograft aortic valve: a 29-year, 99.3\% follow up of 1,022 valve replacements. The Journal of Heart Valve Disease, 10(3), 334-344; discussion 335. 
Pinchuk, L., Wilson, G. J., Barry, J. J., Schoephoerster, R. T., Parel, J.-M., \& Kennedy, J. P. (2008). Medical applications of poly(styrene-block-isobutylene-block-styrene) (“SIBS"). Biomaterials, http://doi.org/10.1016/j.biomaterials.2007.09.041

Rafiee, M. A., Rafiee, J., Wang, Z., Song, H., Yu, Z.-Z., \& Koratkar, N. (2009). Enhanced Mechanical Properties of Nanocomposites at Low Graphene Content. ACS Nano, 3(12), 3884-3890. http://doi.org/10.1021/nn9010472

Ramaswamy, S., Salinas, M., Carrol, R., Landaburo, K., Ryans, X., Crespo, C., ... Yamaguchi, H. (2013). Protocol for Relative Hydrodynamic Assessment of Trileaflet Polymer Valves. Journal of Visualized Experiments, (80). http://doi.org/10.3791/50335

Roberts, W. C., \& Ko, J. M. (2005). Frequency by Decades of Unicuspid, Bicuspid, and Tricuspid Aortic Valves in Adults Having Isolated Aortic Valve Replacement for Aortic Stenosis, With or Without Associated Aortic Regurgitation. Circulation, 111(7), 920-925. http://doi.org/10.1161/01.CIR.0000155623.48408.C5

Roberts, W. C., \& Ko, J. M. (2009). Morphologic Aspects of Valvular Heart Disease. In A. Wang \& T. M. Bashore (Eds.), Valvular Heart Disease (pp. 1-35). Humana Press. Retrieved from http://link.springer.com/chapter/10.1007/978-1-59745-4117_1

Roe, B. B., Kelly, P. B., Myers, J. L., \& Moore, D. W. (1966). Tricuspid Leaflet Aortic Valve Prosthesis. Circulation, 33(4S1), I-124-I-130. http://doi.org/10.1161/01.CIR.33.4S1.I-124

Ruiz, C. E., Iemura, M., Medie, S., Varga, P., Van Alstine, W. G., Mack, S., ... Kiupel, M. (2005). Transcatheter placement of a low-profile biodegradable pulmonary valve made of small intestinal submucosa: A long-term study in a swine model. The Journal of Thoracic and Cardiovascular Surgery, 130(2), 477.e1-477.e9. http://doi.org/10.1016/j.jtcvs.2005.04.008

Sacks, M. S., \& Schoen, F. J. (2002). Collagen fiber disruption occurs independent of calcification in clinically explanted bioprosthetic heart valves. Journal of Biomedical Materials Research, 62(3), 359-371. http://doi.org/10.1002/jbm.10293 
Sadasivuni, K. K., Ponnamma, D., Thomas, S., \& Grohens, Y. (2014). Evolution from graphite to graphene elastomer composites. Progress in Polymer Science, 39(4), 749-780. http://doi.org/10.1016/j.progpolymsci.2013.08.003

Santos, C. M., Mangadlao, J., Ahmed, F., Leon, A., Advincula, R. C., \& Rodrigues, D. F. (2012). Graphene nanocomposite for biomedical applications: fabrication, antimicrobial and cytotoxic investigations. Nanotechnology, 23(39), 395101. http://doi.org/10.1088/0957-4484/23/39/395101

Turi, Z. G. (2004). Mitral Valve Disease. Circulation, 109(6), e38-e41. http://doi.org/10.1161/01.CIR.0000115202.33689.2C

Vyavahare, N., Ogle, M., Schoen, F. J., Zand, R., Gloeckner, D. C., Sacks, M., \& Levy, R. J. (1999). Mechanisms of bioprosthetic heart valve failure: fatigue causes collagen denaturation and glycosaminoglycan loss. Journal of Biomedical Materials Research, 46(1), 44-50.

Wang, A., \& Bashore, T. M. (2009). Valvular heart disease. Dordrecht; New York: Humana Press.

Wang, Q., McGoron, A. J., Bianco, R., Kato, Y., Pinchuk, L., \& Schoephoerster, R. T. (2010). In-vivo assessment of a novel polymer (SIBS) trileaflet heart valve. The Journal of Heart Valve Disease, 19(4), 499-505.

Westaby, S., Horton, M., Jin, X. Y., Katsumata, T., Ahmed, O., Saito, S., ... Grunkemeier, G. L. (2000). Survival advantage of stentless aortic bioprostheses. The Annals of Thoracic Surgery, 70(3), 785-791. http://doi.org/10.1016/S00034975(00)01736-7

Wheatley, D. J., Raco, L., Bernacca, G. M., Sim, I., Belcher, P. R., \& Boyd, J. S. (2000). Polyurethane: material for the next generation of heart valve prostheses? European Journal of Cardio-Thoracic Surgery, 17(4), 440-448. http://doi.org/10.1016/S1010-7940(00)00381-X

Yin, W., Gallocher, S., Pinchuk, L., Schoephoerster, R. T., Jesty, J., \& Bluestein, D. (2005). Flow-induced Platelet Activation in a St. Jude Mechanical Heart Valve, a Trileaflet Polymeric Heart Valve, and a St. Jude Tissue Valve. Artificial Organs, 29(10), 826-831. http://doi.org/10.1111/j.1525-1594.2005.29109.x 